\title{
PRODUÇÃO DE POLPA CELULÓSICA A PARTIR DE ENGAÇO DE BANANEIRA
}

\author{
MARIA DE LOURDES APARECIDA PRUDENTE SOFFNER
}

Economista Doméstico

Orientador: Prof. Dr. FRANCIDES GOMES DA SILVA JÚNIOR

Dissertação apresentada à Escola Superior de Agricultura "Luiz de Queiroz", Universidade de São Paulo, para obtenção do título de Mestre em Ciências, Área de Concentração: Ciência e Tecnologia de Madeiras.

\author{
PIRACICABA \\ Estado de São Paulo - Brasil \\ Julho - 2001
}


Dados Internacionais de Catalogação na Publicação (CIP) DIVISÃO DE BIBLIOTECA E DOCUMENTAÇÃO - Campus “Luiz de Queiroz”/USP

\author{
Soffner, Maria de Lourdes Aparecida Prudente \\ Produção de polpa celulósica a partir de engaço de bananeira / Maria de \\ Lourdes Aparecida Prudente Soffner. - - Piracicaba, 2001. \\ 56 p. : il. \\ Dissertação (mestrado) - - Escola Superior de Agricultura Luiz de Queiroz, \\ 2001. \\ Bibliografia. \\ 1. Engaço de bananeira 2. Polpa de celulose 3. Polpação 4. Resíduo agrícola I. \\ Título
}

CDD 676.12

"Permitida a cópia total ou parcial deste documento, desde que citada a fonte - $\mathrm{O}$ autor" 


\section{DEDICATÓRIA}

Ao meu marido Renato, pelo amor, carinho, cooperação, compreensão e incentivo. Sempre com muita paciência.

Aos meus filhos Júlia e Ricardo, que souberam acompanhar a mãe nesta jornada com muito carinho e alegria.

Aos meus pais Pedro e Domitilla (in memoriam) pelo amor e dedicação com que me ensinaram a enfrentar a vida, sempre com fé, simplicidade, entusiasmo e coragem.

\section{HOMENAGEM}

Aos bananicultores do Brasil e àpopulação que atende àessa atividade. 


\section{AGRADECIMENTOS}

Ao Prof. Dr. Francides Gomes da Silva Júnior (Departamento de Ciências Florestais/ESALQ/USP) pelo seu interesse, apoio e dedicação constantes na orientação geral deste trabalho.

Ao Conselho Nacional de Desenvolvimento Científico e Tecnológico (CNPq) pela bolsa de estudo.

Aos professores do LCF/ESALQ pela colaboração, incentivo e amizade durante o período do mestrado, para a minha formação e para a realização deste trabalho, em especial ao Prof. Dr. José Otávio Brito (Chefe do LCF), Prof. Dr. Luiz Ernesto George Barrichelo, Prof. Dr Mário Tomazello Filho (Coordenador do Curso de Pós-graduação do ciclo de 1998) e Prof. Dr. Adriana Maria Nolasco.

À Distribuidora de Bananas Magário S.A. (Vale do Ribeira) pelo fornecimento do engaço de bananeira para este estudo.

À Nogueira S.A. - Máquinas Agrícolas (Itapira/SP) pelo empréstimo da ensiladora desagregadora utilizada na etapa de beneficiamento primário.

Ao Prof. Dr. Luiz Balastreire, chefe do Departamento de Engenharia Rural da ESALQ/USP, pela disponibilidade do local, do motor e de funcionários para realização do processamento primário do engaço.

Ao Laboratório de Química, Celulose e Energia/LCF/ESALQ por ter posto à disposição suas dependências, funcionários, estagiários e materiais para a realização deste trabalho. À Maria Regina Buch, Udemilson Luiz Ceribelli, Anne Caroline dos Santos, aos estagiários e aos colegas da pósgraduação (Carla dos Santos, Gláucia S. B. de Alencar, Ana Maria Meira). 
Aos funcionários da secretaria do LCF/ESALQ pelo apoio (Fátima, Margarete, Danilo e Alexandre).

Ao Sr. Geraldo José Zenid (Divisão de Produtos Florestais-IPT), pela disponibilidade dos funcionários e reagentes. Aos funcionários Antônio Carlos Franco Barbosa (Laboratório de Anatomia de Madeiras) pelo preparo dos cortes histológicos do engaço e das lâminas, e Sérgio Bravolin (Agrupamento de Preservação de Madeiras) pelo apoio na obtenção das imagens dos planos.

À Prof. Dr. Beatriz A. da Glória (Chefe do Departamento de Ciências Biológicas/ESALQ/USP) pela disponibilidade do Laboratório de Anatomia Vegetal, para realização de imagens dos cortes histológicos. À Marli K. M. Soares pelas orientações sobre uso do equipamento.

Ao Prof. Dr. Cláudio Angeli Sansígolo (FCA/UNESP) pela colaboração nas etapas dos planos da dissertação.

Ao Prof. Dr. Marcos Milan (LER/ESALQ) pelas revisões, pelo suporte no estudo de desfibradoras, pelos conselhos e amizade.

Aos bibliotecários da ESALQ, em especial à Eliana M. Garcia (Central), e Maria Alice Poggiani e Paulo S. Beraldo (IPEF - Institudo de Pesquisa e Estudos Florestais) pelo apoio àrevisão das normas da dissertação.

À Prof. Dr. Maria Elisa de P. E. Garavello (LAN/ESALQ) pela oportunidade de realizar a viagem técnica àCosta Rica e pelo incentivo.

Ao Prof. Dr. João A. Scarpare Filho (ESALQ) e ao Dr. Ricardo A. Kluge pelas referências bibliográficas sobre bananicultura e ao apoio sobre os termos técnicos.

Ao Prof. Dr. Salim Simão pelos ensinamentos sobre a cultura da banana, pelas viagens técnicas ao Vale do Ribeira e Avaré e pelo incentivo.

À Deus pela saúde, força e otimismo para realizar este trabalho.

O sucesso na vida profissional futura depende de muita fé, dedicação e entusiasmo no presente

- L. E. G. Barrichelo 


\section{SUMÁRIO}

Página

LISTA DE FIGURAS................................................................... viii

LISTA DE TABELAS.................................................................

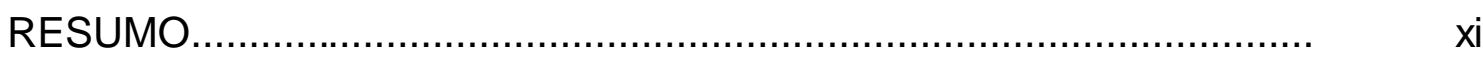

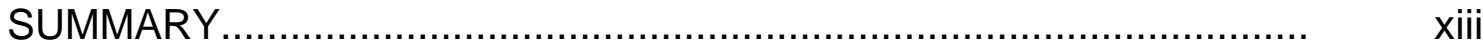

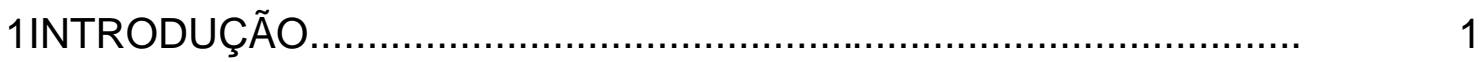

2 REVISÃO DE LITERATURA..........................................................

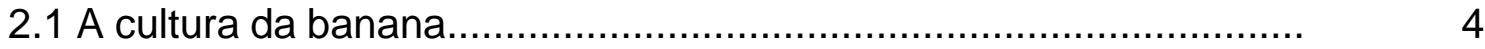

2.1.1 Origem, dispersão e classificação................................................

2.1.2 Panorama da bananicultura.....................................................

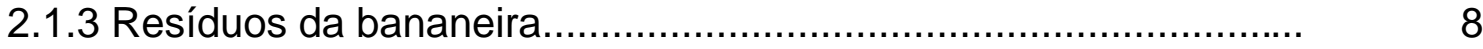

2.2 Produção de polpa celulósica a partir de resíduos da bananeira..... 11

2.3 Características do engaço para produção de polpa celulósica.......... 12

2.4 Pré-tratamentos e processos de polpação para fibras nãomadeiras.......................................................................... 13

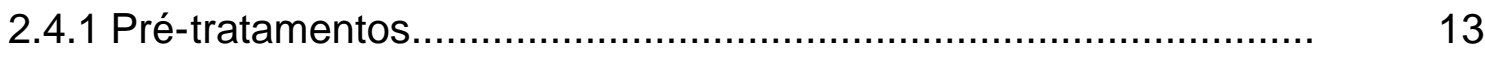

2.4.2 Processos de polpações utilizados em plantas não-madeiras....... $\quad 15$

3 MATERIAL E MÉTODOS............................................................... 19

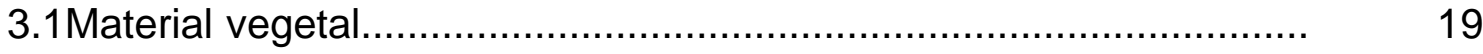

3.2 Caracterização anatômica, morfológica e química do engaço........... 19 
3.3 Processamento primário do engaço ................................................ 21

3.3.1 Caracterização física e química do bagaço.................................. 22

3.4 Pré-tratamentos para polpação.......................................................... 23

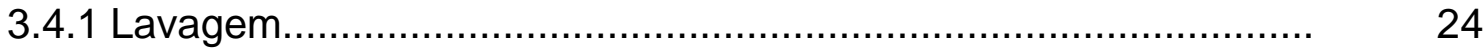

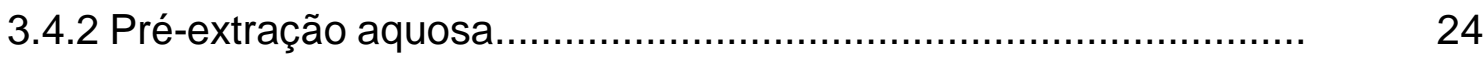

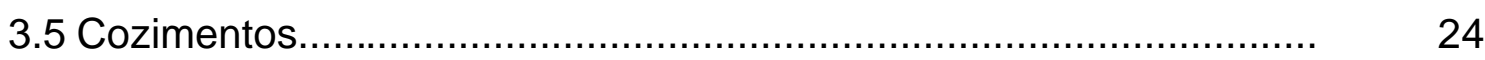

3.5.1 Polpação cal..................................................................... 25

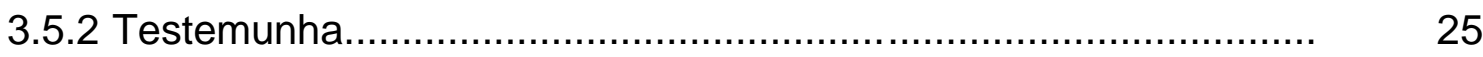

3.6 Parâmetros estabelecidos para avaliação dos cozimentos............... 25

4 RESULTADOS E DISCUSSÃO....................................................... 26

4.1 Caracterização do engaço da bananeira........................................ 26

4.1.1 Morfologia............................................................................... 26

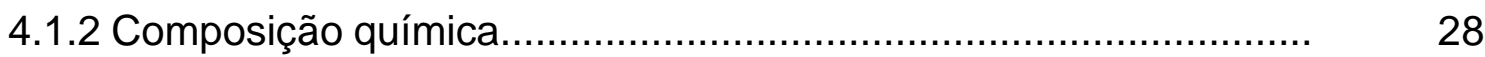

4.1.3 Estrutura anatômica............................................................ 29

4.1.3.1 Dimensões das fibras.......................................................... 31

4.2 Processamento primário do engaço............................................... 34

4.3 Pré-tratamentos.................................................................... 38

4.4 Polpação ......................................................................... 41

4.5 Fluxograma de unidade industrial............................................... 46

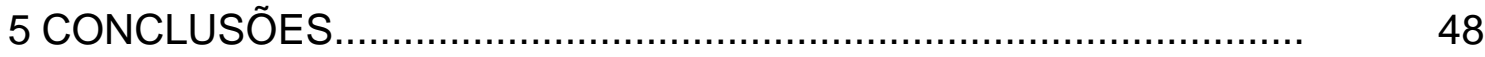

REFERÊNCIAS BIBLIOGRÁFICAS.................................................. 50 


\section{LISTA DE FIGURAS}

Página

1 Origem e distribuição da banana (Soto Ballestero, 1992)................... 5

2 Partes da bananeira, Musa sp......................................................... 6

3 Fluxograma da geração de resíduos da bananicultura 9

4 Esquema dos cortes histológicos do engaço de bananeira, Musa sp. 20

5 Desfibradora (ensiladora desagregadora), Marca Nogueira, Modelo

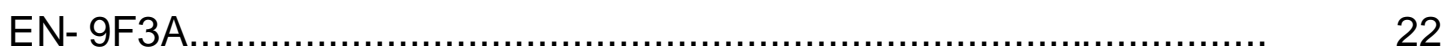

6 Engaço de bananeira, Musa cavendishii, cultivar nanicão................... 27

7 Plano transversal do centro (7a) e da periferia (7b) do engaço de bananeira, $M$ cavendishii, cultivar nanicão. (1) vasos, (2) células de parênquima e (3) feixes fibrosos - aumento/100x........................... $\quad 30$

8 Histograma da frequência da classificação do comprimento das

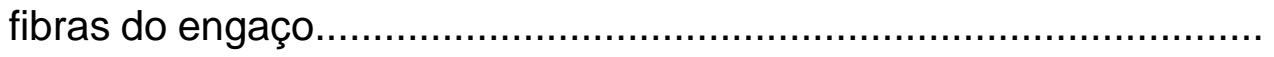

9 Engaço processado mecanicamente, denominado de "bagaço", $M$. cavendishii, cultivar nanicão........................................................ $\quad 35$

10 Composição química do engaço e do bagaço.................................... 37

11 Eficiência de remoção de extrativos do bagaço pelos tratamentos: lavagem, pré-extração aquosa e lavagem seguida de pré-extração

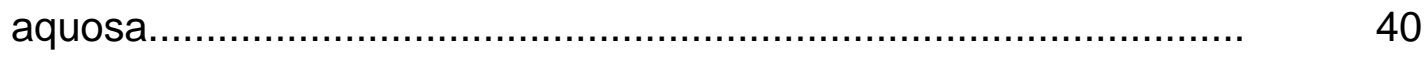

12 Filtro atmosférico (Smook, 1994)................................................ 41

13 Rendimentos - Polpação cal $(\mathrm{CaO})$ - Bagaço original (sem 
tratamento) e bagaço lavado......................................................

14 Teor de lignina residual em função da carga alcalina....................... 43

15 Eficiência de deslignificação em função da carga alcalina................ 44

16 Carga específica de $\mathrm{CaO}$ - t de $\mathrm{CaO} / t$ de lignina inicial................... 45

17 Fluxograma básico de unidade de produção de polpa celulósica a partir do engaço de bananeira....................................................... 


\section{LISTA DE TABELAS}

Página

1 Parâmetros para caracterização do engaço e metodologias.............. 21

2 Relações entre dimensões de fibra.................................................. 23

3 Características morfológicas do engaço de bananeira, $M$. cavendishii, cultivar nanicão....................................................... 27

4 Composição química do engaço de bananeira, M. cavendishii, cultivar nanicão......................................................................

5 Dimensões das fibras do engaço de bananeira, M. cavnedishii, cultivar nanicão ............................................................... 31

6 Composição química do bagaço do engaço de bananeira, $M$. 36

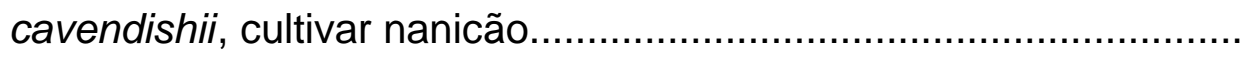

7 Rendimentos e composições químicas dos bagaços tratados........... 


\title{
PRODUÇÃO DE POLPA CELULÓSICA A PARTIR DE ENGAÇO DE BANANEIRA
}

\author{
Autora: MARIA DE LOURDES APARECIDA PRUDENTE SOFFNER \\ Orientador: Prof. Dr. FRANCIDES GOMES DA SILVA JÚNIOR
}

\section{RESUMO}

O engaço de bananeira, suporte que sustenta o cacho de bananas, normalmente é descartado após a colheita da fruta, seja nas casas de embalagens (packing houses) ou em centros distribuidores, onde é considerado verdadeiro resíduo pelo grande volume gerado e por não ser aproveitado. Por essa razão e por constituir-se em material fibroso, o engaço foi avaliado para produção de polpa celulósica. O engaço in natura apresenta cerca de $93 \%$ de umidade e células de parênquima em abundância; em termos de composição química, o engaço apresenta $7,4 \%$ de lignina, $47,8 \%$ de extrativos totais, e $47,6 \%$ de holocelulose. Nesta pesquisa, a performance do engaço como matéria-prima para produção de polpa celulósica foi avaliada, usando o $\mathrm{CaO}$ como fonte álcali. Foram utilizadas lavagem e pré-extração aquosa $\left(100^{\circ} \mathrm{C}\right.$, por 100 minutos) como pré-processos com o propósito de reduzir a grande 
quantidade de extrativos no bagaço do engaço de bananeira. $O$ bagaço original e os materiais obtidos após os pré-processos foram submetidos à polpação com $\mathrm{CaO}$ com 8, 10, 12 e 14\% de $\mathrm{CaO}$, à temperatura de $120{ }^{\circ} \mathrm{C}$ por 120 minutos em digestor rotativo. Para comparação foi utilizado o processo soda de polpação, sob as mesmas condições, usando-se $12 \%$ de $\mathrm{NaOH}$ como carga alcalina. Os resultados mostraram que a aplicação da lavagem e pré-extração aquosa ocasionaram a redução de cerca de $40 \%$ da massa inicial do bagaço. Considerando-se as condições de polpação e também a composição química do engaço de bananeira, os pré-processos avaliados não apresentaram um significativo efeito no processo de cozimento. Para a polpação do engaço, o processo de polpação cal pode ser considerado uma alternativa técnica para produção de polpa celulósica, apresentando níveis de deslignificação similar ao do processo de polpação soda. 


\title{
PULP PRODUCTION FROM BANANA STEM
}

\author{
Author: MARIA DE LOURDES APARECIDA PRUDENTE SOFFNER \\ Adviser: Prof. Dr. FRANCIDES GOMES DA SILVA JÚNIOR
}

\section{SUMMARY}

The banana stem, grain stalk that supports the banana fruits, is normally discarded after the fruit harvesting, either in the "packing house" or in the delivering centers, where it is considered a residue due to the great volume generated. For this reason and for being a fibrous material, stem was evaluated for pulp production. The stem in natura presents $93 \%$ of humidity and parenchymatic cells in abundance; in terms of chemical composition the stem presents $7,4 \%$ of lignin, $47,0 \%$ of total extractives and $45,6 \%$ of holocelullose. In this research, the performance of the ste $m$ as raw material for pulp production was evaluated, using the $\mathrm{CaO}$ as an alkali source. Washing and aqueous preextraction ( $100^{\circ} \mathrm{C}$ and 100 minutes) were considered as a pre-process in order to reduce the amount of extractives on the banana stem bagasse; the original bagasse and the materials obtained after the pre-processes were submitted to the $\mathrm{CaO}$ pulping with $8,10,12$ and $14 \%$ of $\mathrm{CaO}$, at $120^{\circ} \mathrm{C}$ temperature during 120 minutes in rotating digester. For comparison, a soda cooking was carried 
out, under the same conditions using $12 \%$ of $\mathrm{NaOH}$ as alkaline charge. The results showed that the aplication of washing and aqueous pre-extraction caused a reduction of about $40 \%$ in the initial mass of bagasse. Considering the pulping conditions and also the chemical composition of the banana stem bagasse the pre-process evaluated did not show a significant effect on the cooking process itself. For the banana stem pulping, a $\mathrm{CaO}$ process can be considered a technical alternative for pulp production, with delignification rates similar to the $\mathrm{NaOH}$ process. 


\section{INTRODUÇÃO}

A produção mundial de banana é de aproximadamente 64,6 milhões de t/ano. A Índia ocupa o primeiro lugar com 13,9 milhões de t/ano, em segundo lugar encontra-se o Equador com 6,8 milhões de t/ano e em terceiro lugar encontra-se o Brasil com 6,3 milhões de t/ano (FAO, 2001).

A cultura da banana está distribuída por todo o território brasileiro. Os principais estados produtores dessa fruta são Pará, São Paulo, Bahia, Amazonas, Minas Gerais e Santa Catarina. As espécies de banana mais cultivadas são Musa sapientum, cultivar prata; e Musa cavendishii, cultivares nanica e nanicão. Cerca de $90 \%$ da produção destina-se ao mercado interno para comercialização da fruta in natura e para fins industriais.

O estado de São Paulo, segundo maior produtor de banana do país, possui uma área cultivada de aproximadamente 50.170 ha (Anuário Estatístico Brasileiro, 1998). A espécie mais difundida é a Musa cavendishii, cultivares nanica e nanicão, as quais possuem um rendimento médio de 1214 cachos/hectare. A produção do estado de São Paulo está concentrada na Divisão Regional Agrícola (DIRA) do município de Registro, que compreende a área abrangida pelo Vale do Ribeira e litoral sul do estado. Essa região é a maior produtora de banana do Estado, com uma área cultivada de cerca de 40.445 ha (Arruda et al., 1993). 
A cultura da banana gera grande quantidade de resíduos após a colheita da fruta, sendo considerados os mais importantes em termos de grande volume gerado e de potencial fibroso o pseudocaule, a folha e o engaço. Os pseudocaules e as folhas normalmente são utilizados no solo como cobertura morta, para manter a sua umidade e evitar erosão, controlar plantas daninhas e retornar nutrientes à planta. Essa forma de aproveitamento contribui para minimizar custos com adubação dessa cultura. $O$ engaço não tem sido aproveitado, sendo descartado no processo de separação das pencas na casa de embalagem (packing house) e disposto sobre o solo, geralmente em área urbana, ou descartado no lixo doméstico. Esta forma de disposição contribui para a geração de sérios problemas ambientais e fitossanitários, e implica em custos com transportes.

Os resíduos da bananeira frutífera cultivada, Musa sp, o pseudocaule, o engaço e a folha, têm sido utilizados, há muito tempo, em artesanatos com a palha e a fibra, para a produção de cordas, tapetes, chapéus, cestos, tecidos e papéis especiais e artesanais em vários países como: Brasil, Costa Rica, Equador, Filipinas. No Brasil foram realizadas pesquisas visando verificar os potenciais de aplicação desses resíduos em materiais de construção, indústria automotiva, artigos têxteis e produção de polpa celulósica e papéis artesanais.

Um bananal conduzido de maneira convencional pode fornecer 200 t/ha/ano de restos de cultura, compreendendo pseudocaules, engaços e folhas. O peso médio do engaço segundo Kluge et al. (1999) é de 2,26kg, representando $8 \%$ do cacho. Com isso, a quantidade de engaço disponível no estado de São Paulo é de cerca de 4,72 t/ha/ano, totalizando aproximadamente 236.800 t/ano de engaço in natura, e 16.580 t/ano de matéria seca.

A possibilidade de aproveitamento do engaço na produção de polpa celulósica representa uma alternativa interessante para as regiões produtoras de banana. Trata-se de um material com potencial fibroso, o qual pode ser classificado como matéria-prima não madeireira para produção de polpa celulósica de fibra longa, agrupado como resíduo agrícola, proveniente de 
planta anual, da classe das monocotiledôneas. Normalmente as matériasprimas não madeireiras possuem baixo teor de lignina, quando comparado às madeiras, o que proporciona facilidade nos processos de polpação e branqueamento.

O uso do engaço como matéria-prima para produção de polpa celulósica possibilita agregar valor a um resíduo, transformando-o em subproduto, polpa celulósica, o que contribui para a minimização de impactos ambientais negativos. $\mathrm{Na}$ Costa Rica os rejeitos da bananicultura são descartados no mar pelos produtores. No Brasil grande parte dos resíduos permanece nos bananais favorecendo o desenvolvimento de organismos biodeterioradores e de animais peçonhentos. Do ponto de vista tecnológico, o engaço representa uma fonte alternativa de fibra longa para produção de papéis especiais.

No entanto, para viabilizar a produção em escala industrial é necessário o desenvolvimento de tecnologias adequadas para a polpação do engaço, já que muitas culturas de banana estão localizadas próximas à áreas de preservação ambiental, como é o caso da Região do Vale do Ribeira, no Estado de São Paulo. Países como o Equador e a Costa Rica possuem pequenas indústrias de produção de polpas celulósicas e papéis especiais e artesanais de engaço de bananeira.

Tendo em vista o benefício que pode advir do aproveitamento do engaço tanto do ponto de vista ambiental como econômico, o objetivo deste trabalho foi avaliar o potencial de uso do engaço de bananeira Musa sp, para produção de polpa celulósica, através do processo de polpação cal. 


\section{REVISÃO DE LITERATURA}

\subsection{A cultura da banana}

\subsubsection{Origem, dispersão e classificação}

A palavra banana tem origem africana e é conhecida também pelos nomes banano, plátano, gruneo e cambure (Soto Ballestero, 1992). A banana é considerada uma das primeiras frutas utilizadas na alimentação humana e tem origem na Ásia (Simmonds, 1959; Medina et al., 1985).

A dispersão da cultura da banana pelo mundo está ligada ao período do descobrimento. Supõe-se que os navegantes portugueses, através das suas viagens, conheceram essa fruta e começaram a cultivá-la por onde passavam (Soto Ballestero, 1992).

A distribuição geográfica da cultura econômica da bananeira está compreendida entre as latitudes de $25^{\circ} \mathrm{N}$ e $25^{\circ} \mathrm{S}$, embora sejam encontradas até $34^{\circ} \mathrm{N}$ em Israel e $30^{\circ} \mathrm{S}$ em Natal, na África. Nem todas as regiões dentro dessa faixa apresentam condições favoráveis ao plantio comercial, quer por questões de temperatura, em função da altitude, quer por escassez e má distribuição da precipitação pluvial (Medina,1961).

A bananeira é uma planta perene e possui ciclo vegetativo com desenvolvimento de forma contínua e acelerada. É uma planta muito exigente em relação ao clima, principalmente em relação à temperatura e à umidade, sendo o recomendado um índice pluviométrico mensal de $100 \mathrm{~mm} \mathrm{e}$ temperatura de $27^{\circ} \mathrm{C}$. A oscilação desses índices pode implicar na redução no 
desenvolvimento da planta (Moreira, 1987). O período compreendido entre o plantio e a colheita do fruto pode oscilar de 12 a 18 meses (Simão, 1971).

A origem e distribuição geográfica da banana estão representadas na Figura 1.

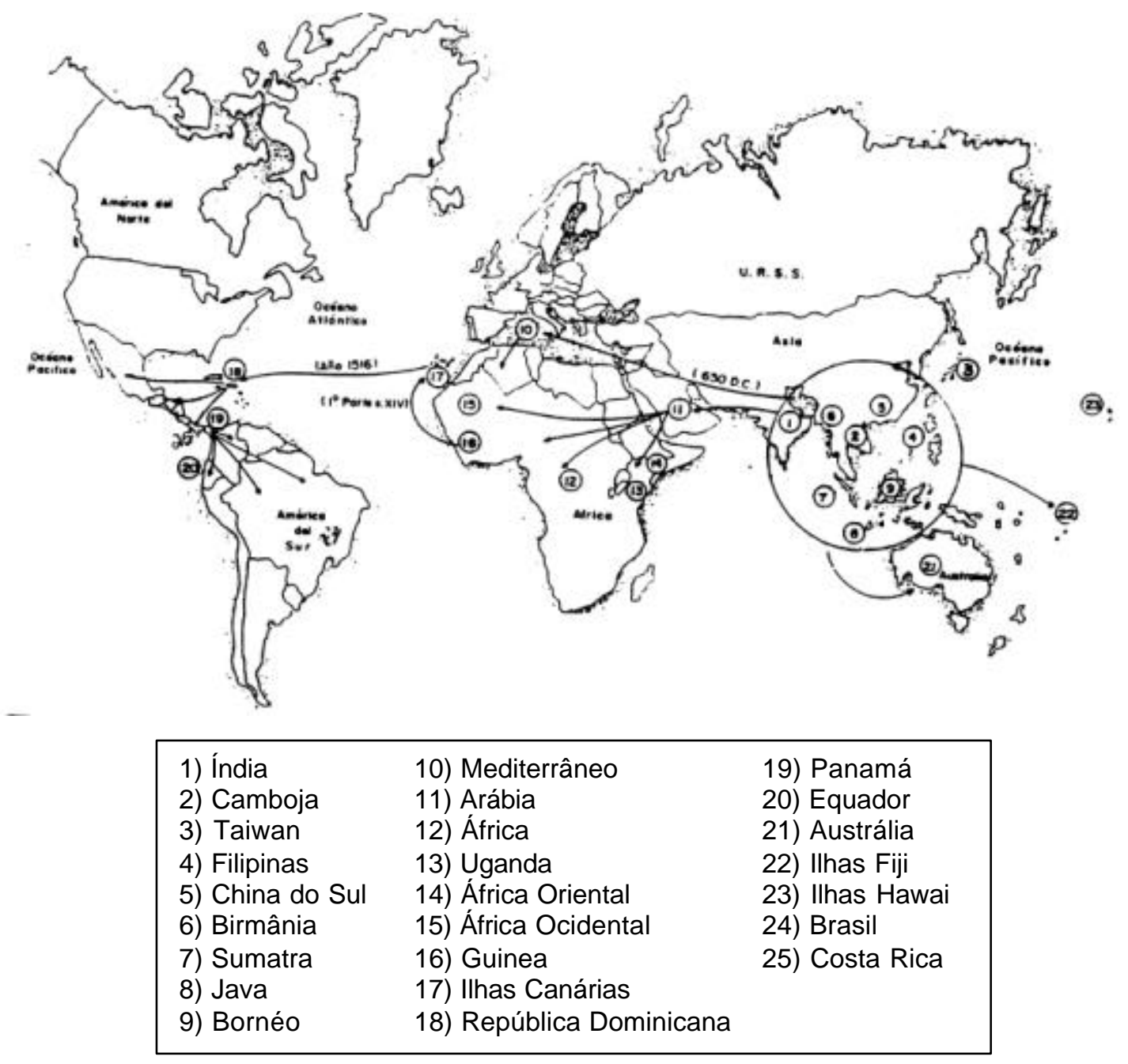

Figura 1 - Origem e distribuição da banana (Soto Ballestero, 1992)

A bananeira pertence à divisão Agiospermae (= Magnoliophyta), classe Monocotyledoneae (= Lilipsida), ordem Scitaminae (= Zigiberales) e família Musaceae (Engler, 1954; Cronquist, 1981). A família Musaceae é constituída por dois gêneros: Musa (bananas comestíveis) e Ensete (bananas 
silvestres). O primeiro apresenta 35 espécies e o segundo, um total de 7 espécies (Rochelle et al., 1991).

O gênero Musa ainda pode ser dividido em 4 subgêneros: Australimusa, Rhodochlamys, Callimusa e Eumusa. Os subgêneros Callimusa e Rhodochlamys não produzem frutos comestíveis. O subgênero Australimusa contém apenas uma espécie, conhecida como abacá (Musa textilis), que é utilizada em alguns países para extração de fibras têxteis das bainhas foliares. No subgênero Eumusa, ou simplesmente Musa, é onde se encontram as espécies de interesse comercial (Simmonds, 1966)

O grupo mais cultivado no mundo é o Cavendishii, que compreende vários cultivares. No Brasil as cultivares mais difundidas desse grupo são nanica e nanicão (sub grupo "Giant Cavendishii" triploide AAA).

A bananeira é um vegetal herbáceo completo, típico das regiões tropicais úmidas, que possui raiz, caule subterrâneo, folhas, flores, frutos e sementes (Figura 2).

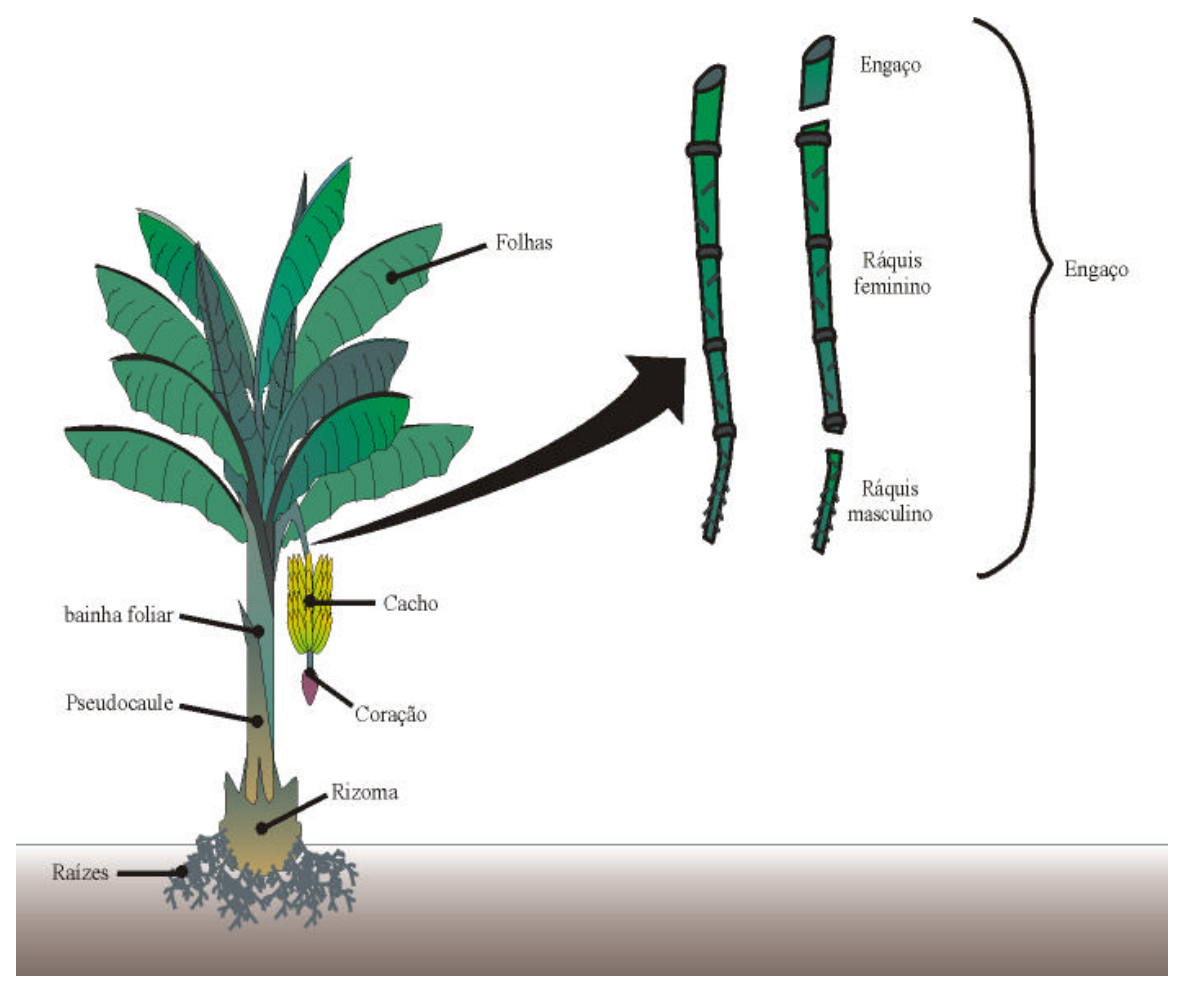

Figura 2 - Partes da bananeira, Musa sp 
O caule, ou rizoma, é subterrâneo, nele ocorre a formação das raízes, das folhas, da inflorescência e a geração de novos rebentos ou "filhotes".

O pseudocaule é um estirpe ou "tronco" em formato de um cilindro irregular, formado por bainhas foliares sobrepostas, tendo em seu interior o "palmito" ou coração central. No prolongamento das bainhas foliares encontram-se as folhas. O cacho é composto pelas partes: engaço, ráquis, pencas de bananas e botão floral ou "coração" (Medina, 1961).

O engaço é o pedúnculo da inflorescência, que tem início no ápice do pseudocaule e termina na inserção da primeira penca. $O$ ráquis é o eixo de inflorescência, que inicia no ponto onde termina o engaço e alonga-se até o local de inserção do botão floral. As flores femininas formarão os frutos e estão inseridas no ráquis feminino, que inicia no ponto onde inicia a primeira penca e estende-se até a última. As flores masculinas estão no ráquis masculino, a partir do ponto de inserção da última penca e termina no botão floral (Soto Balestero, 1992).

O eixo que sustenta o cacho de bananas é conhecido no Brasil como engaço ou ráquis e na língua inglesa ele é denominado "peduncle", "rachis", "stalk" ou "stem" (Simmonds, 1966).

A penca é formada pelo conjunto de frutos ou dedos, estruturadas em duas fileiras horizontais e paralelas. O ponto de fusão dos pedúnculos recebe 0 nome de "almofada". O conjunto de flores masculinas ainda em desenvolvimento é conhecido como botão floral ou "coração" (Simão, 1971).

Os tamanhos das partes da bananeira dependerão da espécie, cultivar, condições edafoclimáticas e tratos culturais.

\subsubsection{Panorama da bananicultura}

A produção mundial de banana está estimada em 64,6 milhões de t/ano, sendo a Índia o maior produtor mundial, com 13,9 milhões de t/ano, 
ocupando uma área de 445.000 ha cultivados. Em segundo lugar está o Equador com 6,8 milhões de t/ano, com 213.000 ha cultivados. O Brasil ocupa a terceira posição produzindo 6,3 milhões de t/ano, com área plantada de aproximadamente 523.900 ha (FAO, 2001).

A cultura da banana está distribuída por todo o território nacional, participando com significativa importância na economia de diversos estados brasileiros. Sendo os maiores produtores: Pará, São Paulo, Bahia, amazonas, Minas Gerais, e Santa Catarina (Anuário Estatístico Brasileiro, 1998).

Nos últimos anos, a bananicultura tem sido deslocada para regiões não tradicionais de cultivo. Atualmente, podemos encontrar bananais em todas as regiões do Brasil, desde as faixas litorâneas até as regiões de planalto (Anuário Estatístico do Brasil, 1996).

A bananicultura apresenta elevada importância social e econômica em algumas regiões, possuindo papel importante como fonte de alimentação, fixação de mão-de-obra no campo e geradora de divisas para o país.

Os principais fatores que afetam diretamente o setor produtivo da atividade bananicultora são: a alta competitividade dos países desenvolvidos que imperam sobre o mercado exportador por deterem as novas tecnologias; a baixa produtividade dos países que aplicam manejo cultural inadequado, pela escassez de recursos econômicos; a incidência de pragas e moléstias que se alastram devastando bananais.

\subsubsection{Resíduos da bananeira}

A idéia usual de resíduo ou "o que sobra", decorre da agregação aleatória de elementos bem definidos que, quando agrupados, transformam-se em uma massa sem valor comercial e com potencial de agressão ambiental variável segundo a sua composição (Figueiredo, 1995). 
No Brasil, a denominação de "resíduo sólido" inclui as descargas de materiais sólidos provenientes das operações industriais, comerciais, agrícolas e das atividades da comunidade (Figueiredo, 1995).

As principais objeções aos resíduos sólidos nas sociedades de consumo se enquadram em cinco categorias: saúde pública, estética, ocupação do espaço, custo de recolhimento-processamento e degradação de recursos naturais. Estes ítens representam custos de mão-de-obra, transporte, energia e comprometimento do bem estar e do ambiente (Nolasco, 1993 ).

A geração de resíduos da atividade bananicultora está representado na Figura 3.

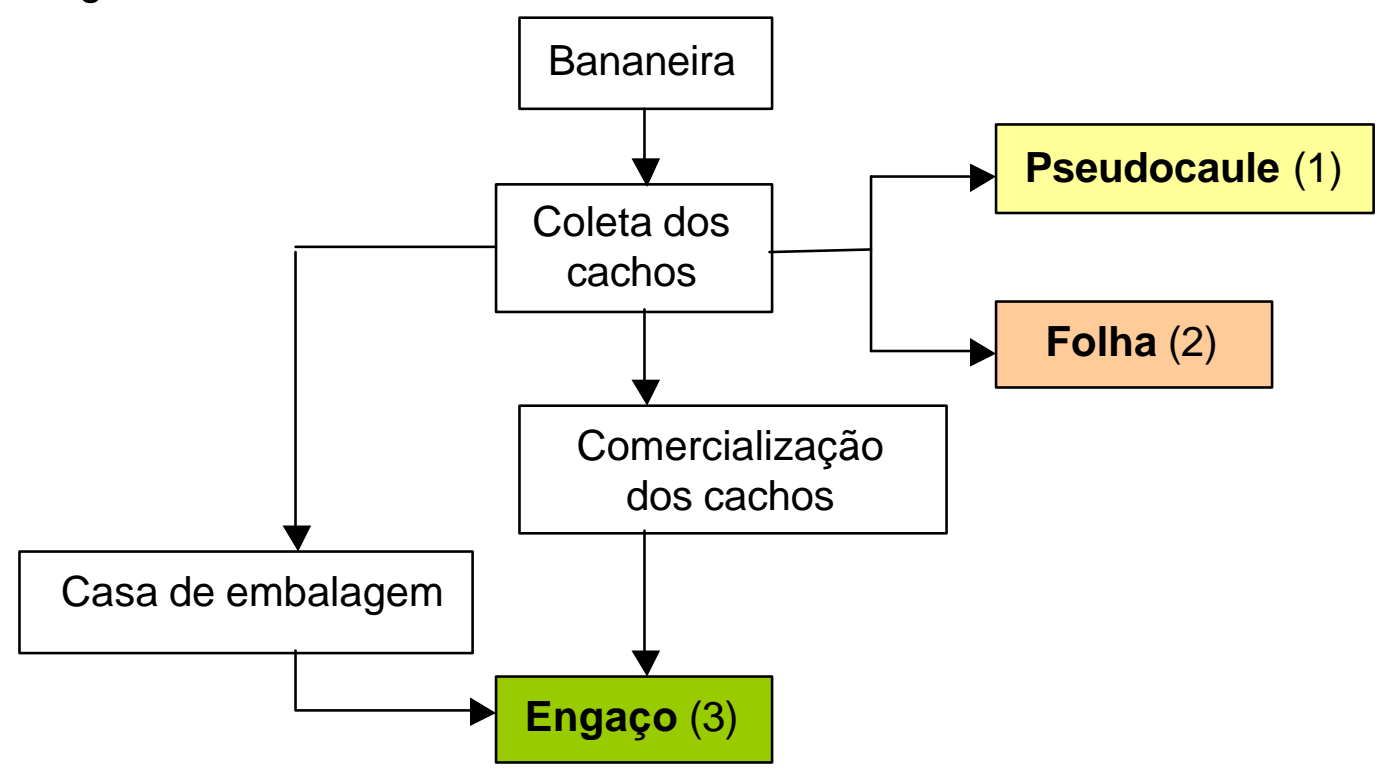

Figura 3 - Fluxograma da geração de resíduos da bananicultura

$\mathrm{Na}$ atividade bananicultora, após a colheita da fruta, o cacho é conduzido para outros locais e as outras partes da planta permanecem no bananal. A planta entra em senescência e morre, encerrando o ciclo vegetativo, tornando-se resto de cultura ou resíduo agrícola. 
O cacho é deslocado para outros locais e as outras partes da planta, como pseudocaule, folhas e coração, normalmente permanecem mo bananal, sendo utilizadas como cobertura no solo.

O pseudocaule e a folha, após a colheita da fruta, normalmente são utilizados no solo, como cobertura morta, para manter a umidade, evitar erosão, controlar plantas daninhas e devolver nutrientes ao solo para reduzir custos de adubação.

O engaço normalmente é descartado no processo de separação das pencas, nas casas de embalagem (packing house), onde são realizadas a seleção, a limpeza e a classificação da fruta. Outro ponto de descarte do engaço são os centros distribuidores, onde esse material fica disposto sobre o solo, geralmente em área urbana, ou acrescentado ao lixo doméstico. De acordo com Blanco Rojas (1996), o engaço possui rápida decomposição, devido à sua alta umidade, cerca de $93 \%$, a sua composição química favorece a proliferação de insetos e microorganismos biodegradadores. O acúmulo de engaço gera sérios problemas ambientais e fitossanitários, pelo volume gerado.

Simmonds (1966) mencionou que o engaço era utilizado na Costa Rica como cobertura de solo, porém os custos com seu deslocamento e manuseio não compensavam essa prática.

Segundo Gowen (1996) as partes da bananeira, grupo Cavendishii, concentram os seguintes nutrientes: na raiz, $\mathrm{Mg}$ e $\mathrm{Zn}$; no rizoma, $\mathrm{Cu}$, $\mathrm{Fe}$ e $\mathrm{Al}$; no pseudocaule, N, Mn, Ca e Mg; na folha, K, S, B, Cl, Zn, Cu e P; no engaço $\mathrm{N}$; e P no fruto.

De acordo com Hiroce (1972), após a colheita da fruta, a atividade bananicultora pode gerar em matéria seca, para o grupo Cavendishii: 8 t/ha de pseudocaule, 4,7 t/ha de folha; 0,7 t/ha de engaço e 0,3 t/ha de botão floral ou coração.

Simmonds (1959) relatou que o engaço representa de 8,6 a $12,6 \%$ do peso do cacho; enquanto na Costa Rica o engaço compreende de 6,7 a 7,36\% do cacho, os quais oscilam entre 22,8 a $38,4 \mathrm{~kg}$ para o grupo Cavendishii. 
Kluge et al. (1999) obteve uma média para o peso do engaço de $8 \%$ do peso do cacho para o mesmo grupo. De acordo com a densidade de plantio, podem ser retiradas do bananal de 3,14 a 6,30 t/ha de engaço com cerca de 93\% de umidade, ou então 0,22 a 0,44 t/ha de engaço seco.

\subsection{Produção de polpa celulósica a partir de resíduos da bananeira}

Muitas espécies de bananeiras, do gênero Musa, têm sido exploradas para comercialização em pequena escala das fibras "técnicas" ou "comerciais" do pseudocaule, que constituem-se em feixes fibrosos com comprimentos relacionados com o comprimento do pseudocaule. Há muitos anos vem sendo averiguada a viabilidade técnica para produzir polpa celulósica a partir dos resíduos da bananeira, principalmente do pseudocaule e do engaço.

A espécie Musa textiles ou abacá, é cultivada principalmente para produção de fibras têxteis de seu pseudocaule, pois seu fruto não é explorado para consumo humano. Essa fibra é conhecida comercialmente como abacá ou cânhamo de Manila. Além das Filipinas é cultivada comercialmente em menor escala em Bornéo, Sumatra e alguns países da América Central. Nas Ilhas Filipinas o abacá era usado para manufatura de tecidos para roupas em geral. Essa fibra é muito indicada para produção de produtos artesanais como bolsas, sacolas e chapéus. Os pseudocaules de bananeiras frutíferas também possuem fibras têxteis, que podem ser exploradas comercialmente (Medina, 1959; Hiroce, 1972; Jarman et al., 1977, Soffner et al., 1999).

O pseudocaule do abacá é utilizado para produzir um papel com elevada resistência, denominado manila paper, empregado na fabricação de sacos para acondicionamento de farinhas, cimento, cal e artigos semelhantes. No Japão, a fibra do abacá é utilizada para manufatura de um papelão resistente, usado na construção de paredes e móveis (Medina, 1959).

Países produtores de banana como a Costa Rica e o Equador possuem tecnologias para produzir papéis com fibra de bananeira. A Costa 
Rica, um dos maiores exportadores mundiais de banana, tem utilizado o engaço como fonte de matéria-prima na produção de papéis de impressão na proporção de $10 \%$ de fibra de engaço e $90 \%$ de aparas, e também para produção de papéis artesanais (Garavello \& Soffner, 1997).

\subsection{Características do engaço para produção de polpa celulósica}

Blanco Rojas (1996) avaliou polpas celulósicas a partir do engaço de bananeira, obtidas pelos processos sulfato, soda e termomecânico e concluiu que esse material possui grande potencial para ser utilizado na produção de polpa celulósica e papel, principalmente para fins que requeiram resistência.

As fibras do engaço de bananeira, sub grupo "Giant cavendishii", possuem comprimento médio de $7 \mathrm{~mm}$ e largura média de $40 \mu \mathrm{m}$ (Blanco Rojas, 1996). Sabório (1981) considera essa fibra apropriada para produzir papéis de embalagem e cartão, por possuir propriedades como resistência, espessura e porosidade.

A composição química do engaço de bananeira foi averiguada por Shedden (1978) e Torres (1981), para o cultivar "Giant cavendishii". O teor de lignina encontrado foi $11,73 \%$ e os teores de holocelulose e hemiceluloses foram $53,5 \%$ e $15 \%$, respectivamente. Os resultados dessas pesquisas apontaram que esse material é apropriado para produzir polpas celulósicas através do processo de polpação mecânico.

De acordo com estudos realizados por Sheddem (1978) e Torres (1981) o baixo teor de holocelulose encontrado nas espécies do gênero Musa reduz o rendimento dos processos químicos de polpação. $O$ valor obtido para lignina foi considerado baixo, $8 \%$, quando comparado aos teores para madeira, na faixa de 25 a $35 \%$ (Brito, 1985). 


\subsection{Pré- tratamentos e processos de polpação para fibras não-madeiras}

Historicamente os primeiros papéis para escrita foram produzidos a partir de plantas não-madeiras, ou denominadas de plantas anuais. Atualmente essas plantas representam uma alternativa para países com baixa disponibilidade de madeiras, e também aos que dispõem de resíduos agrícolas fibrosos ou culturas de plantas fibrosas não-madeiras como: abacá (Musa textiles), bananeira (Musa sp), bambu (Bambusa vulgaris), fórmio (Phormium tenax), juta (Corchorus capsularis), linho (Linum usitatissimum), rami (Bochemeria nivea), sisal (Agave sisalana), bagaço de cana-de-açúcar (Saccharum officinarum), palha de arroz (Oriza sativa), palha de trigo (Triticum aestivum) (Rodéz, 1984).

O uso de plantas não-madeiras como fonte de matéria-prima para produção de polpa celulósica e papel tem sido crescente, especialmente nos trópicos, onde a disponibilidade de materiais de fibra longa é pequena (Darkwa, 1998). A utilização dessas plantas na fabricação de polpa celulósica pressupõe uma desagregação das estruturas de seus elementos construtivos, mediante processos físicos, químicos ou biotecnológicos, ou usando processos mistos decorrentes de uma participação conjunta e equilibrada dos processos (Barrichelo \& Brito, 1976).

\subsubsection{Pré- tratamentos}

Antes do processo de polpação propriamente dito, algumas fibras nãomadeiras necessitam de pré-tratamentos, que podem ser mecânicos ou químicos, para a retirada de materiais indesejáveis, constituídos por tecidos parenquimáticos e elementos de vasos, que são denominados de "medula". Esses constituintes dificultam o processo de polpação e implicam em perda de qualidade da polpa celulósica. Esses tratamentos facilitam o processo de deslignificação, reduzem o consumo de reagentes químicos e melhoram 0 rendimento e a qualidade da polpa (Blanco Rojas, 1996). 
Atchison (1987b) afirma que o beneficiamento de material nãomadeira deve ser economicamente viável e realizado por ação mecânica. No caso da bananeira é necessário reduzir ou mesmo eliminar a medula. A proporção entre medula e fibra é de 70/30 (Darkwa, 1988). O engaço de bananeira pode ser beneficiado mecanicamente, em moinho de martelos, o qual provoca a desagregação no engaço in natura, preparando-o para produção de polpa celulósica (Blanco Rojas, 1996).

As fibras têxteis do rami e o bagaço de cana são beneficiados por processos físicos ou por ação de água quente, através da lavagem e posterior centrifugação para eliminar substâncias solúveis em água (Benatti Junior, 1986; Abel-Rehim \& Tarabousi, 1987)

Fernandes et al. (1981) mostraram que o pseudocaule de bananeira possui $38 \%$ de material mucilaginoso. Esse material dificulta o processo de deslignificação e a lavagem da polpa, e ainda resulta no escurecimento da polpa celulósica e obstrução de feltros e telas. Estes autores recomendaram, portanto, a remoção desses materiais antes do processo de polpação, tratandose o pseudocaule com $2 \%$ de ácido clorídrico, considerado ácido fraco, o qual não afetará significativamente as propriedades da fibra. Esse ácido foi utilizado por apresentar custo inferior ao ácido sulfúrico, que também poderia ser utilizado para esse fim. O material resultante desse tratamento constitui-se de $35 \%$ de fibra bruta.

Darkwa (1978) tratou o pseudocaule com $\mathrm{NaOH}$ a 1 e $2 \%, \mathrm{HCl}$ a $1 \%$, $\mathrm{Na}_{2} \mathrm{SO}_{3}$ a $1 \%$ e com $0,5 \%$ de di-octil sulfoccionato de sódio, seguido de tratamento mecânico em refinador de disco para separação de células de parênquimas e componentes minerais.

Para o beneficiamento do bagaço de cana-de-açúcar Abel-Rehim \& Tarabolsi (1987) utilizaram cal ("lime") e afirmaram que ela é efetiva para romper as ligações entre a medula e as fibras. Este processo pode ser considerado como um primeiro estágio no processo de polpação deste material, resultando numa diminuição do consumo de reagentes químicos. 
Montalvão et al. (1984) aplicaram o estágio de pré-extração aquosa para colmos de bambu, com o objetivo de eliminar parte dos extrativos, facilitar a polpação kraft posterior, favorecer a destruição das células parenquimáticas, as quais afetam desfavoravelmente as resistências físicas e mecânicas da polpa celulósica; promover redução de álcali durante o estágio de polpação, facilitar a ligação entre as fibras e favorecer as resistências físicas e mecânicas da polpa. Os resultados mostraram que houve remoção parcial dos extrativos por meio desta etapa, redução de cargas alcalinas na polpação kraft e efeitos favoráveis na qualidade da polpa. Para o bambu, a pré-extração aquosa solubilizou cerca de $80 \%$ dessas substâncias à $140^{\circ} \mathrm{C}$.

A pré-hidrólise aquosa pode ser utilizada no processo de polpação kraft. Este processo consiste em tratar a matéria-prima com vapor d'água ou soluções ácidas diluídas, 0,2 a 0,5\%, e altas temperaturas, de 165 a $175^{\circ} \mathrm{C}$, visando remover as hemiceluloses. A pré-hidrólise é utilizada em processos de produção de polpas solúveis, onde se deseja produzir polpas com alto grau de pureza, com alto teor de $\alpha$-celulose, utilizadas para a produção de derivados da celulose como rayon (Costa et al., 1998).

\subsubsection{Processos de polpações utilizados em plantas não-madeiras}

A obtenção da polpa celulósica constitui a primeira etapa da produção de papel. Sob o ponto de vista técnico, o termo "polpa celulósica" compreende o resíduo fibroso proveniente da deslignificação parcial ou total da matéria-prima vegetal empregada (Foelkel \& Barrichelo, 1975).

Os processos de produção de polpa celulósica podem ser classificados em ácidos ou alcalinos (Grant, 1966; Foelkel \& Barrichelo, 1975; D'Almeida, 1988). Para os vegetais não-madeiras os processos de polpação mais utilizados são os alcalinos.

Sob o ponto de vista ecológico, praticidade e economia, os processos de polpação mais recomendados são: mecânico, termomecânico e cal $(\mathrm{CaO})$. 
Esses processos têm sido empregados há muitos anos e em inúmeros países, para produção de polpas celulósicas a partir de plantas não-madeiras e em resíduos agrícolas em geral (Blanco Rojas, 1996).

Blanco Rojas (1996) utilizou o processo termomecânico para polpação do engaço. O método consistiu primeiramente na eliminação de materiais não fibrosos presentes no engaço em sua forma original e que implicariam na qualidade final do papel, como epiderme, células parenquimáticas, extrativos e cinzas. Os cavacos foram cozidos em água por 3 horas à $98{ }^{\circ} \mathrm{C}$, realizando a separação física dos materiais indesejados. Numa segunda etapa, o material foi refinado mecanicamente produzindo polpa celulósica. Por esse processo obteve-se um rendimento global de aproximadamente $31 \%$ de polpa em relação ao peso seco do engaço.

Rydholm (1965) afirma que o $\mathrm{Ca}(\mathrm{OH})_{2}$ foi uma das primeiras bases a ser utilizada em polpação de palhas, plantas fibrosas e resíduos agrícolas. O processo de polpação cal, descrito por Foelkel \& Barrichelo (1975), é classificado como um processo alcalino, cujo reagente empregado para promover a deslignificação é o hidróxido de cálcio $-\mathrm{Ca}(\mathrm{OH})_{2}$. Normalmente este álcali é empregado para resíduos agrícolas como palhas de cereais, bagaço de cana-de-açúcar. A celulose produzida é do tipo semi-química, a qual apresenta qualidade inferior, e pode ser empregada na fabricação de papelão ondulado (miolo).

Até meados de 1950, a maior parte da polpa celulósica de palha era obtida pelo processo cal, usando digestores esféricos (bola). Estes digestores tinham de 4,30 a 5,50 m de diâmetro, e durante a cocção, aplicava-se vapor direto e girava-se o digestor ao mesmo tempo (Atchison et al., 1976).

De acordo com Grant (1966), o processo cal é muito utilizado quando se quer evitar uma degradação excessiva na celulose presente em matériasprimas que não contenham muitas impurezas indesejáveis, como ligninas, pectinas, resinas, cêras, taninos, pigmentos vegetais e compostos 
carboidratados, em proporções que podem variar, de acordo com o tipo da matéria-prima vegetal.

O uso da cal como reagente para produção de polpa celulósica tem como vantagens ser um álcali mais fraco que a soda, causando portanto menor dano às fibras, é mais econômica que a soda, a qual é considerada agente contaminante do meio ambiente. A cal é menos eficiente que a soda para reduzir certos tipos de pigmentos que dão cor à polpa, sendo este um fator irrelevante quando o aspecto cor não for de importância para o produto final. Quando se usa a cal para produzir polpa celulósica, corta-se a matéria-prima em pedaço de 3 a $5 \mathrm{~cm}$ de largura e se aquece, a uma pressão de, aproximadamente, 4, $6 \mathrm{~kg} / \mathrm{cm}^{2}$, durante 6 horas, com 13 a $15 \%$ de cal sobre 0 peso da polpa seca ou por cerca de 10 horas a 1,8 a 2,1 kg/cm² (Grant, 1966).

O hidróxido de sódio, ou soda cáustica, é um produto muito útil para deslignificação de matérias-primas vegetais, principalmente para madeiras, palhas de cereais e plantas fibrosas em geral. No processo de polpação soda o agente de deslignificação é a soda $(\mathrm{NaOH})$. Este processo é considerado um dos processos mais antigos, sendo ainda hoje muito empregado em inúmeras indústrias de celulose e papel, de pequeno e médio porte, principalmente naquelas que não dispõem de sistema de recuperação de licor do cozimento. Este processo vem sendo tendenciosamente substituído por outros mais aperfeiçoados (Foelkel \& Barrichelo, 1975).

Durante a II Guerra Mundial, na Jamaica, foi verificada a viabilidade econômica do uso das espécies de bananeiras cultivadas, como a Gross Michel, e Musa balbisiana, para a fabricação de papel resistente, em substituição àfibra de abacá, Musa textiles, utilizando o processo de polpação soda, o qual proporcionou facilidade no processo de branqueamento porém com perdas consideravelmente altas no rendimento, mas por outro lado viável economicamente (Medina, 1959).

Estudos realizados na Guatemala sobre os resíduos da bananeira como pseudocaule, folha e engaço, determinaram a viabilidade técnica e 
econômica da produção de polpa celulósica e papel, em pequena escala, pelos processos químicos sulfato e organossolve, obtendo rendimento de polpa entre 50 e $70 \%$ (ICAITI, 1988b).

Para as plantas da classe das monocotiledôneas, a relação licor/material, geralmente é superior aos índices relatados para polpação de madeira 4:1. Darkwa (1978) utilizou a proporção 5:1 para polpação soda e kraft, e Fernandes et al. (1981) empregou 6:1 para o processo kraft do pseudocaule.

Darkwa (1978) utilizou os processos kraft e soda para produção de polpa celulósica da Musa paradisiaca L. Para o processo kraft obteve-se rendimentos entre 50,4 e 34,5\% e números kappa variando de 58,8 a 9,4. Para o processo soda os rendimentos foram de 47,1 a $34,9 \%$ e número kappa de 52,3 a 9,4 . 


\section{MATERIAL E MÉTODOS}

\subsection{Material vegetal}

Neste trabalho foram utilizados engaços de bananeira, cultivar nanicão, Musa cavendishii, grupo Cavendishii - AAA, subgrupo "Giant Cavendishii". As amostras foram coletadas após a colheita da fruta. Esse material foi fornecido pela distribuidora de bananas Magário, procedente da Fazenda São Carlos de Sete Barras, do Município de Registro - SP - Brasil. Para efeito deste trabalho, o material em estudo foi denominado engaço, a parte que compreende o pedúnculo que inicia no ápice do pseudocaule e alonga-se até o ponto de inserção do botão floral, ou "coração" (Figura 2 e 4).

\subsection{Caracterização anatômica, morfológica e química do engaço}

O engaço foi caracterizado enquanto resíduo, para ser utilizado como matéria-prima para produção de polpa celulósica. Para tanto foram analisadas as características morfológicas e anatômicas, composição química e o teor de umidade.

Foram analisados 100 engaços in natura e aferidos os parâmetros: peso $(\mathrm{kg})$; comprimento $(\mathrm{M})$; diâmetros $(\mathrm{M})$ da base, do centro e do topo. Foram determinadas as médias, valores mínimos e máximos, desvios-padrões e coeficientes de variação.

Para o estudo anatômico do engaço o material foi preparado de acordo com metodologia proposta por Barbosa et al. (1999), e realizado no 
Laboratório de Anatomia e Identificação de Madeiras, da Divisão de Produtos Florestais do Instituto de Pesquisas Tecnológicas de São Paulo (IPT). O esquema de preparo dos corpos de prova e cortes histológicos estão representados na Figura 4.

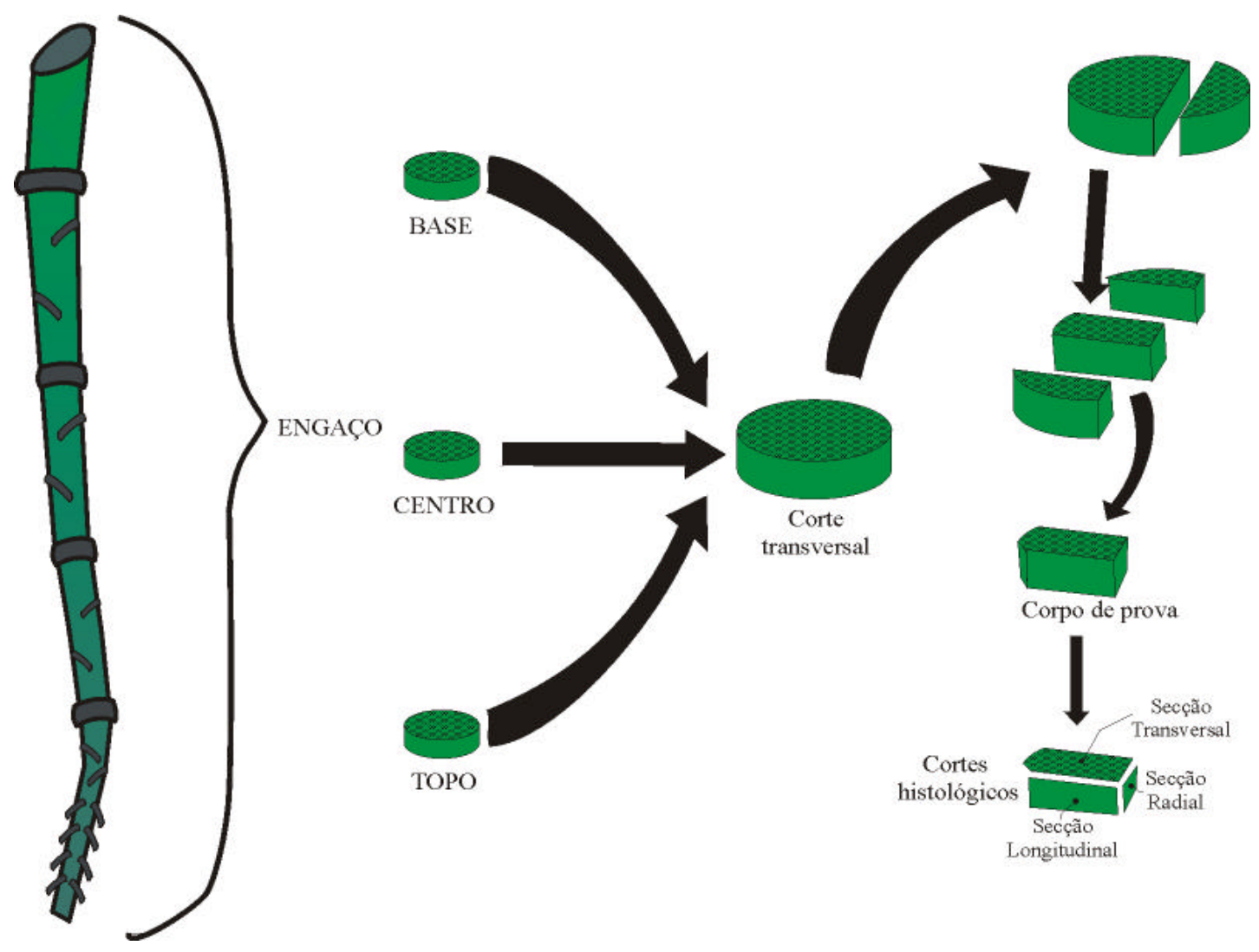

Figura 4 - Esquema dos cortes histológicos do engaço de bananeira, Musa sp

Observação dos cortes histológicos foi realizada em microscópio óptico e os registros das imagens foram realizados em aumento de 100x e em software AnaliSIS, no Instituto de Pesquisas Tecnológicas de São Paulo - IPT e no Laboratório de Anatomia Vegetal do Departamento de Ciências Biológicas ESALQ em software TCHPRO. 
A partir das fotos dos cortes histológicos determinourse a proporção de fibras, vasos e células de parênquima através do método de recorte e pesagem.

$\mathrm{Na}$ Tabela 1 estão os parâmetros para a caracterização física e química do engaço.

Tabela 1. Parâmetros para caracterização do engaço e metodologias

\begin{tabular}{lll}
\hline \multicolumn{1}{c}{ Parâmetros } & \multicolumn{1}{c}{ Metodologia } \\
\hline Teor de umidade (\%) & & ABTCP M2 -71 \\
& Lignina & TAPPI T 13 wd-74 \\
& $\begin{array}{l}\text { Extrativos } \\
\text { totais }\end{array}$ & TAPPI T 1 wd-75; T6 wd-73 \\
Composição Química (\%) & \\
& Holocelulose & Obtida por cálculo* \\
Álcool & TAPPI T6 wd-73 \\
& $\begin{array}{l}\text { Álcool-tolueno } \\
\text { Solubilidade em (\%) }\end{array}$ & TAPPI T6 wd-73 \\
& Água quente & TAPPI T1 wd-75 \\
\hline
\end{tabular}

${ }^{*} 100 \%$ - (\% extrativos totais $+\%$ lignina $)$

\subsection{Processamento primário do engaço}

O processamento primário consistiu em submeter o engaço de bananeira à ação mecânica de uma desfibradora (ensiladora desagregadora), com 3 lâminas, marca Nogueira, Modelo EN-9F3A, acoplada à um motor Yanmar à diesel, com potência de $7,4 \mathrm{~kW}$ (Figura 5). Foi processada aproximadamente uma tonelada de engaço in natura. Após essa etapa, o engaço foi denominado "bagaço". Esse material foi seco ao ar livre, depois seco em estufa à $40^{\circ} \mathrm{C}$, e acondicionado em sacos plásticos, para posteriormente ser submetido aos pré-tratamentos e polpações. 


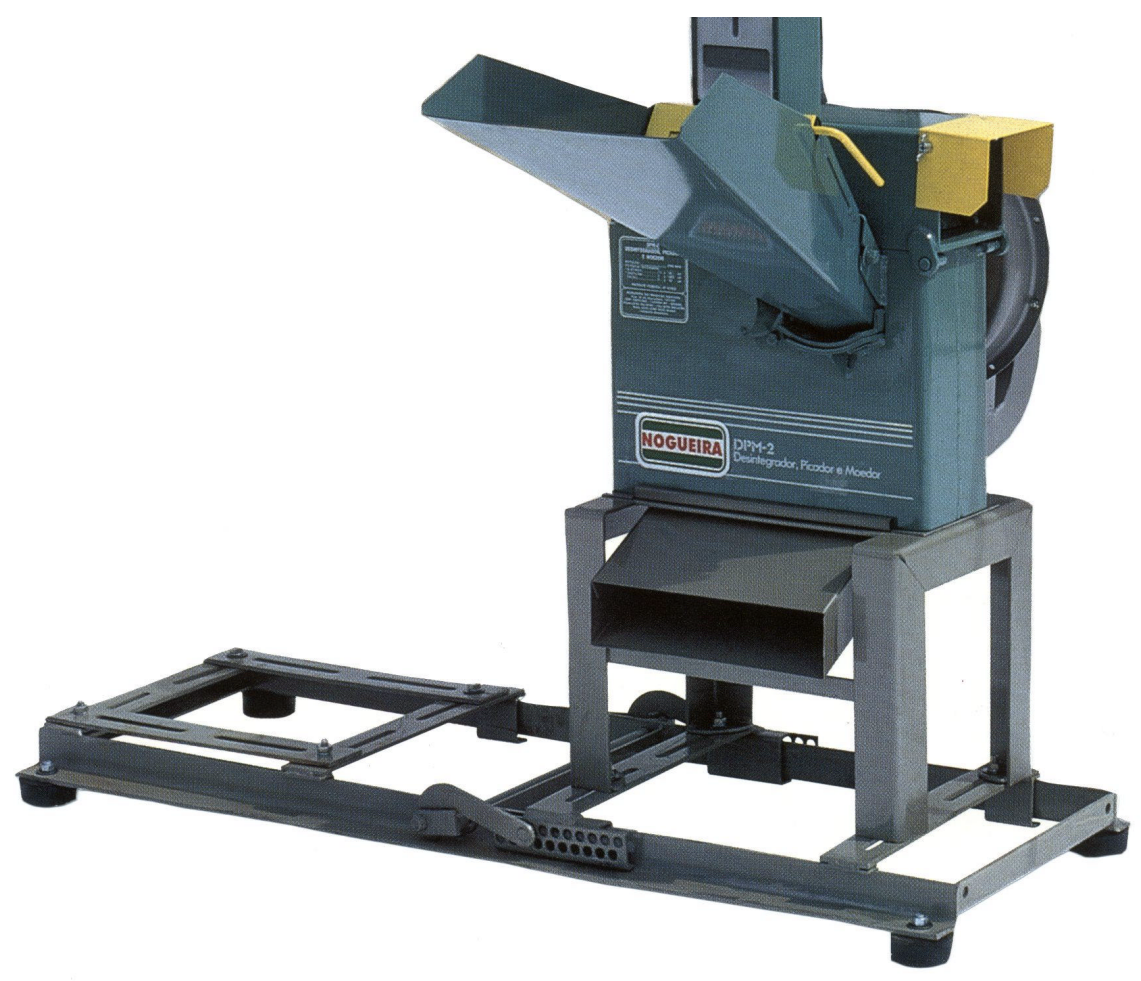

Figura 5 - Desfibradora (ensiladora desagregadora), Marca Nogueira, Modelo EN-9F3A

\subsubsection{Caracterização física e química do bagaço}

O bagaço foi analisado física e quimicamente para verificar suas características para produção de polpa celulósica. Os parâmetros avaliados foram os mesmos apresentados para o engaço na Tabela 1. Também foi avaliado o parâmetro densidade aparente (t. $\mathrm{m}^{-3}$ ), TAPPI T21 wd-82.

Para a análise anatômica foram utilizados $50 \mathrm{~g}$ de bagaço para maceração pelo método água oxigenada, relação 1:1. Para a coloração usou-se safranina e hematoxilina (Tomazello, 1998).

A partir do material macerado foram montadas 15 lâminas, e mensurados os parâmetros de 150 fibras: comprimento $(\mathrm{mm})$, a largura $(\mu \mathrm{m})$, o 
diâmetro do lume $(\mu \mathrm{m})$ e a espessura $(\mu \mathrm{m})$. Os resultados foram apresentados como sendo a média aritmética das 150 mensurações efetuadas para cada dimensão. A espessura da parede (E) foi calculada como a metade da diferença entre a largura da fibra $(L)$ e o diâmetro do lume (DL), conforme a fórmula $\mathrm{E}=(\mathrm{L}-\mathrm{DL}) / 2$. Para cada um dos parâmetros foram verificados os valores mínimos e máximos, desvio padrão e coeficiente de variação. Através dos valores médios das dimensões da fibra foram calculados os parâmetros apresentados na Tabela 2:

Tabela 2. Relações entre dimensões de fibra

\begin{tabular}{ll}
\hline \multicolumn{1}{c}{ Parâmetros } & \multicolumn{1}{c}{ Fórmulas } \\
\hline Coeficiente de flexibilidade $(\mathrm{CF})$ & $\mathrm{CF}=(\mathrm{DL} / \mathrm{L}) \times 100$ \\
Índice de Runkel $(\mathrm{IR})$ & $\mathrm{IR}=2 \mathrm{E} / \mathrm{DL}$ \\
Índice de enfeltramento (IE) & $\mathrm{IE}=(\mathrm{C} / \mathrm{L}) \times 1000$ \\
Fração parede (FP) & $\mathrm{FP}=(2 \mathrm{E} / \mathrm{L}) \times 100$ \\
\hline
\end{tabular}

Onde:

$\mathrm{C}=$ Comprimento da fibra $(\mathrm{mm})$

$\mathrm{L}=$ Largura da fibra $(\mu \mathrm{m})$

$\mathrm{E}=$ Espessura da parede da fibra $(\mu \mathrm{m})$

$\mathrm{DL}=$ Diâmetro do lume da fibra $(\mu \mathrm{m})$

\subsection{Pré-tratamentos para polpação}

O bagaço foi submetido a três pré-tratamentos, que antecederam o processo de polpação propriamente dito, a saber: lavagem, pré-extração aquosa e lavagem seguida de pré-extração aquosa. 


\subsubsection{Lavagem}

A etapa de lavagem do bagaço, como pré-tratamento, foi realizada inicialmente com a hidratação do material, à umidade próxima do bagaço in natura, 93\%, por cerca de 24 horas. Em seguida o material foi processado com consistência de $4 \%$ em liquidificador industrial, marca SIRE, por 5 minutos, e lavado exaustivamente em água corrente, em saco de tecido de microfibra. Foi determinado o rendimento bruto (\%) e a composição química (\%): extrativos totais, lignina, holocelulose.

\subsubsection{Pré-extração aquosa}

A pré-extração aquosa foi realizada sob as seguintes condições:

- Tempo de aquecimento: 40 minutos

- Tempo de cozimento: 100 minutos

- Temperatura: $100^{\circ} \mathrm{C}$

- Relação licor/bagaço: 6:1

Após essa etapa foi averiguado o rendimento bruto do processo (\%) e a composição química do material obtido (\%): extrativos totais, lignina, holocelulose.

\subsection{Cozimentos}

Para os cozimentos foi utilizado um digestor rotativo, de aço inoxidável, com aquecimento elétrico, com capacidade para 20 litros; dotado de 8 cápsulas de aço inoxidável, com capacidade unitária para $550 \mathrm{ml}$. A quantidade de bagaço utilizada foi de 40 gramas absolutamente seco, em cada cápsula. 


\subsubsection{Polpação cal}

Os parâmetros dos cozimentos com cal foram:

- Cargas de álcali : 8, 10,12 e $14 \%$ de Cal - CaO

- Tempo de cozimento: 120 minutos

- Temperatura: $120^{\circ} \mathrm{C}$

- Relação licor / bagaço: $6: 1$

\subsubsection{Testemunha}

Para as testemunhas foram empregadas o processo de polpação soda ( $\mathrm{NaOH})$. Os parâmetros definidos para os cozimentos soda foram:

- Cargas de álcali : $12 \%$ de Soda - $\mathrm{NaOH}$

- Tempo de cozimento: 120 minutos

- Temperatura: $120^{\circ} \mathrm{C}$

- Relação licor / bagaço: $6: 1$

\subsection{Parâmetros estabelecidos para avaliação dos cozimentos}

Os cozimentos foram avaliados quanto aos parâmetros: rendimento bruto (\%), obtido pela relação peso seco/peso úmido e o teor de lignina residual na polpa (\%), ABTCP C 7/71.

A eficiência de remoção de extrativos foi obtida através da relação entre teor de extrativos no material inicial e teor de extrativos no material após tratamento considerando-se o rendimento do processo

A eficiência de deslignificação foi obtida de forma análoga à eficiência de remoção de extrativos 


\section{RESULTADOS E DISCUSSÃo}

\subsection{Caracterização do engaço de bananeira}

$\mathrm{Na}$ avaliação de matérias-primas destinadas à produção de polpa celulósica, faz-se necessária uma caracterização preliminar, que envolve a determinação da composição química e dimensões das fibras do material. No caso do engaço, por se tratar de uma matéria-prima não convencional para esse fim, a caracterização abrangeu também a sua morfologia.

\subsubsection{Morfologia}

$O$ engaço da bananeira é um pedúnculo alongado, possui forma cônica, e é provido de nós nas áreas de inserção das pencas de banana. A base do engaço fica próxima àárea do ápice do pseudocaule e o topo localizase no final de sua extensão, onde inicia-se o "coração", conforme Figura 6. 


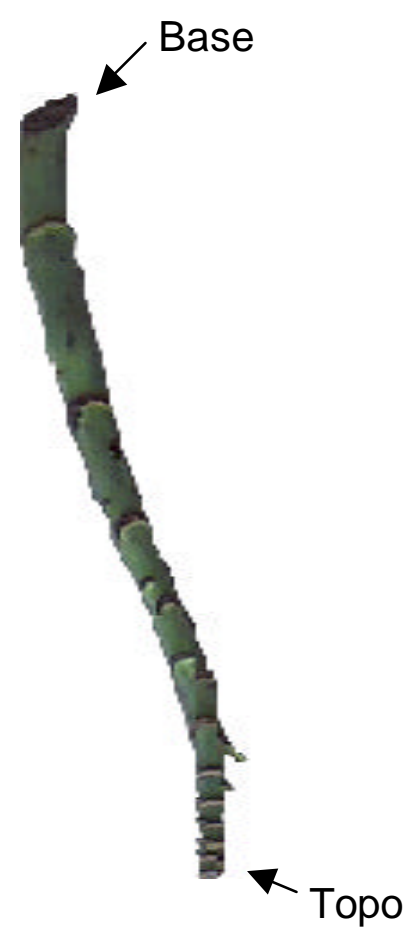

Figura 6 - Engaço de bananeira, Musa cavendishii, cultivar nanicão

A caracterização morfológica do engaço envolveu a determinação do seu comprimento, diâmetro e peso. Os resultados da caracterização morfológica do engaço de bananeira estão apresentados na Tabela 3.

Tabela 3. Características morfológicas do engaço de bananeira, M. cavendishii, cultivar nanicão

\begin{tabular}{|c|c|c|c|c|c|c|}
\hline \multicolumn{2}{|c|}{ Parâmetros } & Média & Mínimo & Máximo & $\begin{array}{l}\text { Desvio } \\
\text { padrão }\end{array}$ & $\begin{array}{c}\text { Coeficiente de } \\
\text { variação (\%) }\end{array}$ \\
\hline \multicolumn{2}{|l|}{ Umidade (\%) } & 92,45 & ---- & ----- & ----- & ----- \\
\hline \multicolumn{2}{|c|}{ Peso úmido (kg) } & 1,48 & 0,53 & 2,62 & 0,44 & 29,91 \\
\hline \multicolumn{2}{|c|}{ Comprimento (m) } & 0,99 & 0,59 & 1,29 & 0,14 & 14,30 \\
\hline & Base & 0,06 & 0,04 & 0,07 & 0,63 & 10,92 \\
\hline \multirow[t]{2}{*}{ Diâmetro (m) } & Centro & 0,05 & 0,03 & 0,06 & 0,58 & 12,27 \\
\hline & Topo & 0,03 & 0,02 & 0,04 & 0,37 & 12,35 \\
\hline
\end{tabular}


O engaço apresenta comprimento médio de aproximadamente 1,00 m, variando de 0,59 à $1,29 \mathrm{~m}$. A média para os diâmetros foi de $0,05 \mathrm{~m}$, tendo os diâmetros da base os maiores valores e os do topo os menores. A média para o peso do engaço foi de 1,48 kg, variando de 0,53 a 2,62 kg. Os resultados são considerados normais para o material em questão, comparando-se com resultados apresentados por Blanco Rojas (1996) e Kluge et al. (1999).

\subsubsection{Composição química}

A avaliação da composição química do engaço de bananeira é de fundamental importância para que este seja considerado como matéria-prima potencial para produção de polpa celulósica, permitindo a orientação da escolha dos processos e tratamentos preliminares. A Tabela 4 apresenta os resultados das características físicas e químicas do engaço de bananeira.

Tabela 4. Composição química do engaço de bananeira, M. cavendishii, cultivar nanicão

\begin{tabular}{lcc}
\hline \multicolumn{1}{c}{ Parâmetros } & Engaço (Teores \%) \\
\hline Extrativos totais & 46,75 \\
Lignina & 8,79 \\
Holocelulose & & 44,46 \\
& Álcool & 10,09 \\
Solubilidade & Álcool-tolueno & 7,55 \\
& Água quente & 30,38 \\
\hline
\end{tabular}

Observa-se grande quantidade de extrativos, quando comparado aos teores para madeira sendo 5 a $8 \%$ para coníferas e 2 a $4 \%$ para folhosas (Brito,1985). A elevada quantidade de extrativos presentes no engaço é 
inconveniente, pois esse componente implicará em consumo de reagentes no processo de polpação e também resultará em baixa qualidade da polpa e rendimento do processo.

O teor de extrativos da bananeira influencia negativamente o uso desta planta na produção de polpa celulósica, por reduzir o rendimento do processo, uma vez que este componente consome carga alcalina, dificultando a polpação (Silva, 1998).

Como a maior parte dos extrativos é solúvel em água, os extrativos presentes no engaço poderiam ser removidos através de um processo de lavagem do material, antes do processo de polpação propriamente dito.

O teor de lignina pode ser considerado baixo quando comparado aos valores obtidos para madeira, 24 a 34\% para coníferas, de 25 a 33\% para folhosas de zonas tropicais, 16 a $24 \%$ para folhosas de zona temperada e 17 a 23\% para gramíneas (D’ Almeida, 1988).

\subsubsection{Estrutura anatômica}

A análise da estrutura anatômica do engaço é de fundamental importância para verificar a frequência e porcentagem de fibras. Os cortes histológicos mostram que o engaço de bananeira possui uma estrutura anatômica típica de plantas monocotiledôneas; presença de feixes fibrovasculares, vasos e grande quantidade de células de parênquima longitudinal. Nas Figuras $7 \mathrm{a}$ e $7 \mathrm{~b}$ são apresentadas as estruturas anatômicas dos planos transversais das regiões do centro e periferia do engaço, respectivamente, obtidas na caracterização. 


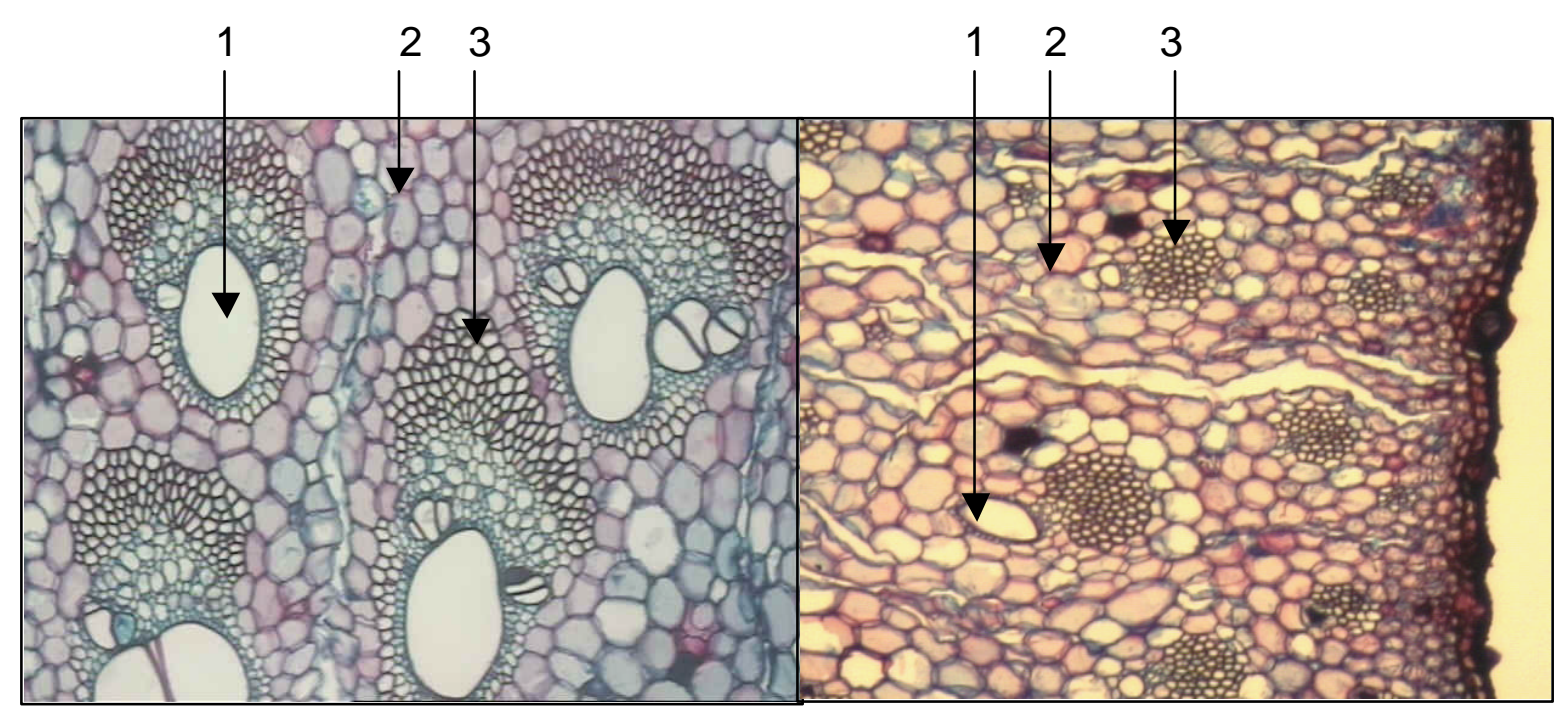

(7a)

(7b)

Figura 7 - Plano transversal do centro (7a) e periferia (7b) do engaço de bananeira, $M$. cavendishii, cultivar nanicão. (1) vasos, (2) células de parênquima e (3) feixes fibrosos - aumento/100 x.

A proporção de fibras no engaço verificada nesta pesquisa foi de $23,9 \%$, enquanto a porcentagem de elementos de vasos foi de $6,5 \%$, e para células de parênquima obteve-se de 69,6\%. Blanco Rojas (1996) relatou que a frequência de fibras no engaço, Musa cavendishii, cultivar nanicão é de $30 \%$ e $70 \%$ para células de parênquima.

Em termos de polpação, os elementos anatômicos mais importantes são as fibras, as quais estão relacionadas com rendimento e qualidade da polpa celulósica. O engaço de bananeira possui baixa proporção de fibras, em comparação com os demais elementos anatômicos. Isto é um grande indicador de que o rendimento esperado para a polpação do engaço seja baixo. Deve-se considerar ainda que a polpa obtida deverá apresentar elevada proporção de células de parênquima, que colaboram para reduzir a ligação inter-fibras e por conseqüência reduzir as resistências mecânicas da polpa. 


\subsubsection{Dimensões das Fibras}

As fibras das monocotiledôneas são em geral finas, cilíndricas e terminadas em ponta aguçada. As dimensões são muito variáveis segundo as espécies e órgão de onde provém (Melo, 1973).

A análise dos resultados das dimensões das fibras do engaço de bananeira, como comprimento, largura, espessura da parede e diâmetro de lume e suas correlações permite avaliar o engaço como matéria-prima para produção de polpa celulósica (Tabela 5).

Tabela 5. Dimensões das fibras do bagaço do engaço de bananeira, $M$. cavendishii, cultivar nanicão.

\begin{tabular}{lrcc}
\hline \multicolumn{1}{c}{ Parâmetros } & Média & D P & CV (\%) \\
\hline Comprimento $(\mathrm{mm})$ & 3,91 & 0,78 & 19,95 \\
Largura $(\mu \mathrm{m})$ & 38,18 & 7,53 & 19,72 \\
Diâmetro de lume $(\mu \mathrm{m})$ & 30,55 & 7,08 & 23,16 \\
Espessura da parede $(\mu \mathrm{m})$ & 3,82 & 1,06 & 27,83 \\
Fração parede & 20,01 & - & - \\
Coeficiente de flexibilidade & 80,02 & - & - \\
Índice de enfeltramento & 102,41 & - & - \\
Índice de Runkel & 0,25 & - & - \\
\hline
\end{tabular}

$\mathrm{DP}=$ Desvio padrão; $\mathrm{CV}=$ Coeficiente de variação

O comprimento médio para a fibra do bagaço do engaço de bananeira foi de 3,91 mm, variando de 2,26 a 6,31 $\mathrm{mm}$.

A maioria dos valores dos comprimentos da fibra do bagaço do engaço estão na faixa de 3 a $4 \mathrm{~mm}$ e de 4 a $5 \mathrm{~mm}$, representando $88,67 \%$ do total dos valores analisados (Figura 8). Isto significa que a maioria da fibra do 
engaço está classificada como muito longa de acordo com a proposta da IAWA (1936) citada por Paula \& Alves (1991).

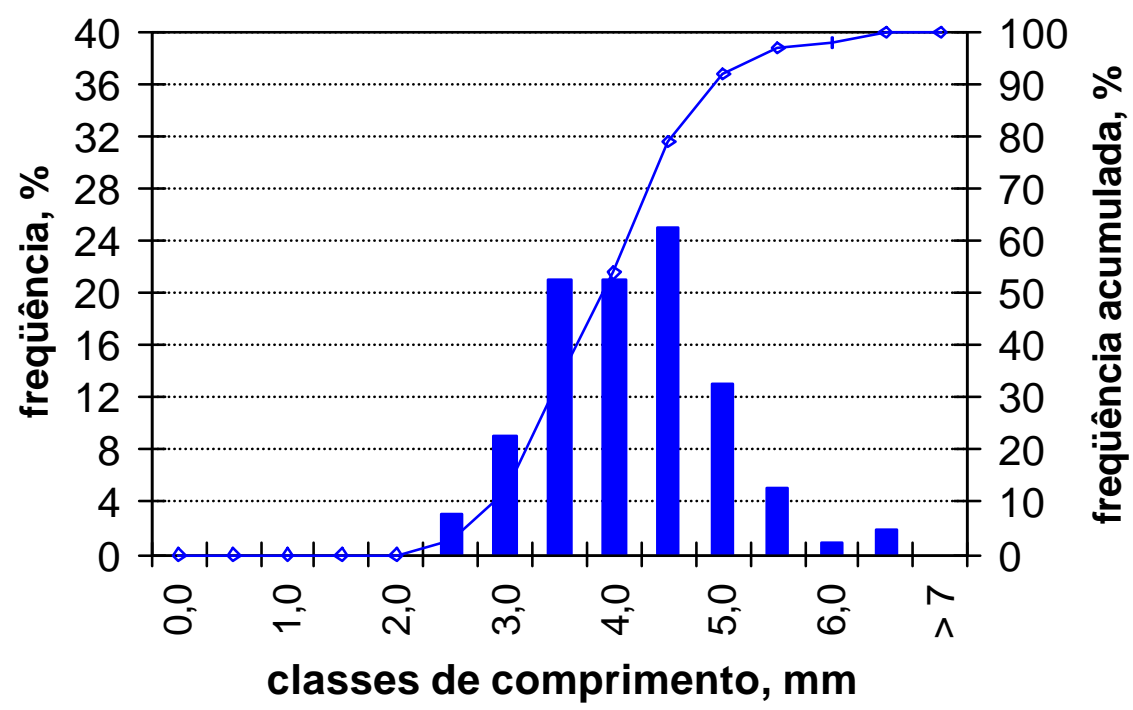

freqüência $\nleftarrow$ freqüência acumulada

Figura 8 - Histograma da frequência da classificação do comprimento da fibra do engaço.

Do ponto de vista papeleiro, Kuan et al. (1988), citado por Silva (1998), relataram que as fibras vegetais geralmente são classificadas como fibras longas quando possuem comprimento médio entre 2 e $5 \mathrm{~mm}$ e como fibras curtas quando possuem comprimento médio entre 0,5 e 1,5 mm. Com base nesta afirmação e nos valores apresentados na Tabela 5, as fibras obtidas do engaço de bananeira, podem ser classificadas como longas.

Admite-se que há uma correlação negativa entre a largura da fibra e resistência ao arrebentamento; o aumento em largura da fibra resulta numa diminuição da resistência ao arrebentamento (Foelkel \& Barrichelo, 1975). A análise da largura das fibras, por si só, apresenta pouco significado prático, sendo mais importante sua avaliação em relação às outras dimensões. 
Maiores diâmetros de lume e paredes menos espessas facilitam o colapso da fibra durante a formação da folha, resultando em maior intensidade de ligações interfibras e consequentemente em propriedades de resistências à tração e ao arrebentamento mais elevadas (Silva, 1998).

Os parâmetros, relacionados às dimensões das fibras, importantes para caracterizá-las para a produção de polpa celulósica são fração parede, coeficiente de flexibilidade, índice de enfeltramento e índice de Runkel (Tabela 5). Estes parâmetros relacionam as dimensões das fibras e permitem uma avaliação mais precisa do que a análise de cada uma das dimensões das fibras isoladamente.

A fração parede, que representa a relação entre espessura e largura da fibra, é o parâmetro que associa-se à flexibilidade e à facilidade de colapso da fibra durante o processo de produção de papel e ligação entre as fibras. Fibras com fração parede acima de 60 são consideradas muito rígidas, e abaixo deste índice 60 possuem boas características para formação de folhas, pois possuem facilidade para sofrerem colapso durante o processo de refino, possibilitando boa flexibilidade, maior superfície de contato entre fibras, proporcionando boas ligações interfibras. O baixo valor para a fração parede pode levar à produção de papéis com baixo volume específico. De acordo com Foelkel (1977), os vegetais fibrosos utilizados na produção de polpa celulósica devem possuir fração parede inferior a $40 \%$.

O engaço de bananeira possui valor de fração parede de $20 \%$, sendo este considerado bastante baixo. Este resultado indica que as polpas celulósicas obtidas a partir deste material devem apresentar baixo volume específico e baixa resistência ao rasgo.

O índice de Runkel é a relação entre duas vezes a espessura da parede da fibra e o diâmetro do seu lume. Este índice é uma característica que está relacionada com a rigidez da fibra e à sua capacidade de interligação. De acordo com a classificação do índice de Runkel, fibras entre 0,25 a 0,50 são consideradas excelente para a fabricação de papel (Paula \& Alves, 1991). 
Quanto menor o índice de Runkel, maior o potencial de ligação entre as fibras, resultando em um maior comprimento de auto ruptura e/ou índice de tração (D’Almeida, 1988). Os valores para índice de Runkel apresentados pelas fibras do engaço de bananeira permitem a classificação destas fibras como excelentes para produção de papel.

\subsection{Processamento primário do engaço}

O engaço de bananeira possui forma original alongada, cônica e levemente curva (Figura 6), o que dificulta sua acomodação em digestores, resultando em espaços vazios e menor massa por volume de digestor, e consequentemente menor rendimento volumétrico em polpa celulósica.

De acordo com os resultados de composição química (Tabela 4), o engaço de bananeira possui grande quantidade de extrativos $(46,75 \%)$, os quais são indesejáveis para a produção de polpa celulósica. Por isso é de fundamental importância viabilizar processos para a remoção destes componentes do engaço.

Considerando-se os fatores citados anteriormente, nesta pesquisa verificou-se a possibilidade de reduzir o engaço de bananeira à partículas menores para facilitar a acomodação do material em digestores e dessa forma aumentar o rendimento volumétrico de polpa celulósica. Para tanto, optou-se por processar o engaço em desfibradora mecânica (ensiladora desagregadora com 3 lâminas e martelos). O engaço foi então reduzido àpequenas partículas e passou a ser denominado "bagaço" (Figura 9). 


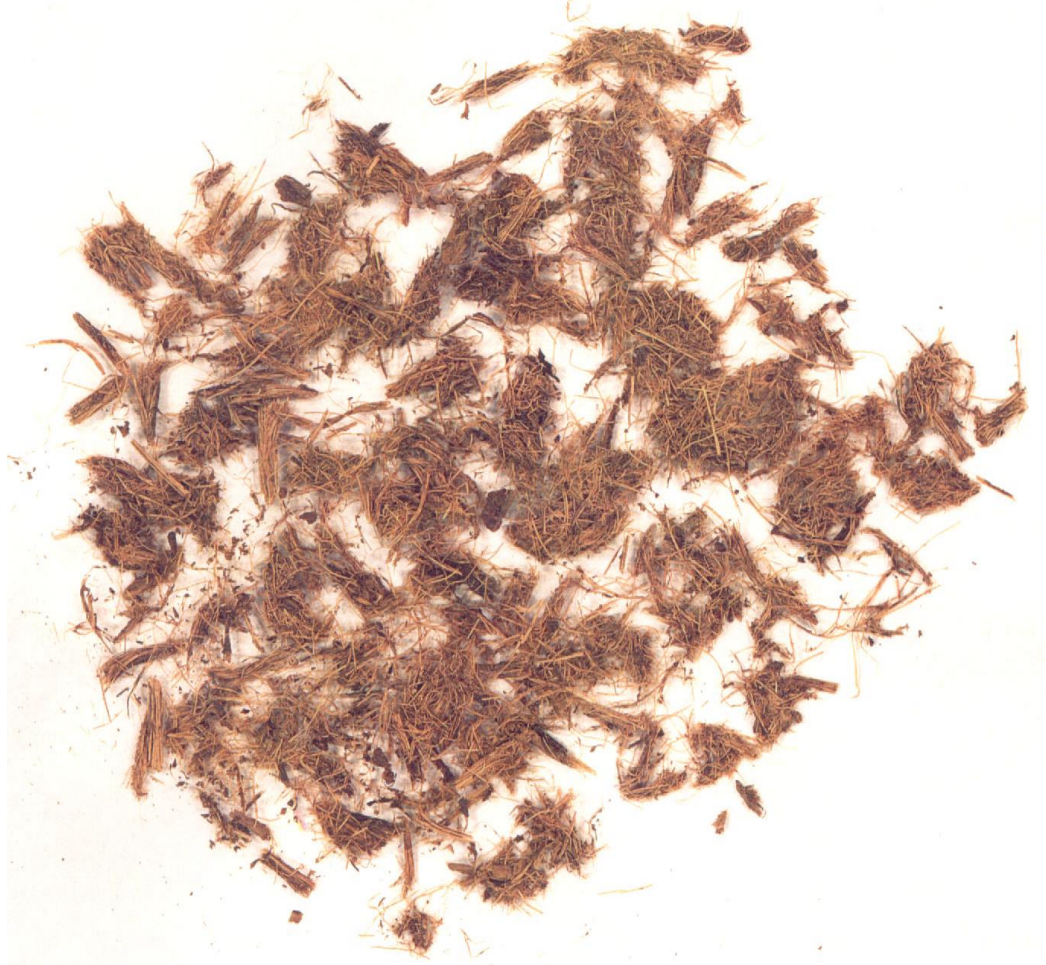

Figura 9 - Engaço processado mecanicamente, denominado de "bagaço", $M$. cavendishii, cultivar nanicão

A transformação do engaço de bananeira em bagaço consiste na desagregação da sua estrutura anatômica por ação mecânica. $O$ engaço foi picado no seu sentido transversal, através de lâminas, resultando em partículas com média de 1,4 cm de comprimento. Em seguida foi desagregado no sentido longitudinal, através da ação de martelos giratórios desprovidos de lâminas.

O bagaço, em relação ao engaço, apresenta como vantagens, um melhor aproveitamento do volume útil de digestores e a possibilidade de secagem e armazenamento serão facilitados, reduzindo assim o efeito da sazonalidade da produção de engaço.

Considerando-se o engaço como matéria-prima para produção de polpa celulósica, a densidade aparente é um parâmetro muito importante, o qual está relacionado diretamente com o aproveitamento dos volumes dos digestores. 
Após o processamento do engaço in natura o material resultante

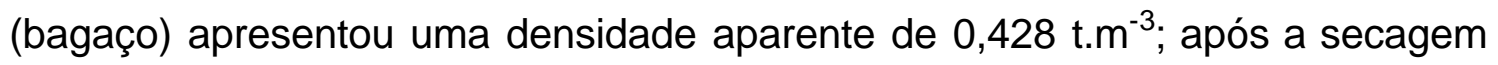
ao ar, de 0,032 t.m $\mathrm{m}^{-3}$ o que caracteriza a alta umidade do material. $\mathrm{O}$ valor baixo para a densidade aparente do bagaço, comparando-o com a densidade aparente média para madeira, $0,170 \mathrm{t} . \mathrm{m}^{-3}$, implica em baixa produção de polpa celulósica, quando os volumes dos digestores são considerados. A composição química do bagaço está apresentada na Tabela 6.

Tabela 6. Composição química do bagaço do engaço de bananeira, $M$. cavendishii, cultivar nanicão

\begin{tabular}{llc}
\hline \multicolumn{1}{c}{ Parâmetros } & Bagaço \\
\hline Extrativos totais (\%) & & 47,0 \\
Lignina (\%) & & 7,4 \\
Holocelulose (\%) & 45,6 \\
& & 12,7 \\
Solubilidade em (\%) & Álcool & 8,5 \\
& Álcool-tolueno & 46,5 \\
& Água quente & 0,428 \\
Densidade aparente $\left(\mathrm{t}^{-3}{ }^{-3}\right)$ & Seco & 0,032 \\
\hline
\end{tabular}

A comparação da composição química do engaço (Tabela 4) com a composição química do bagaço apresentado na Tabela 6 , indicam que o processamento primário, proposto nesta pesquisa, não alterou a composição química original, como mostra a Figura 10. 


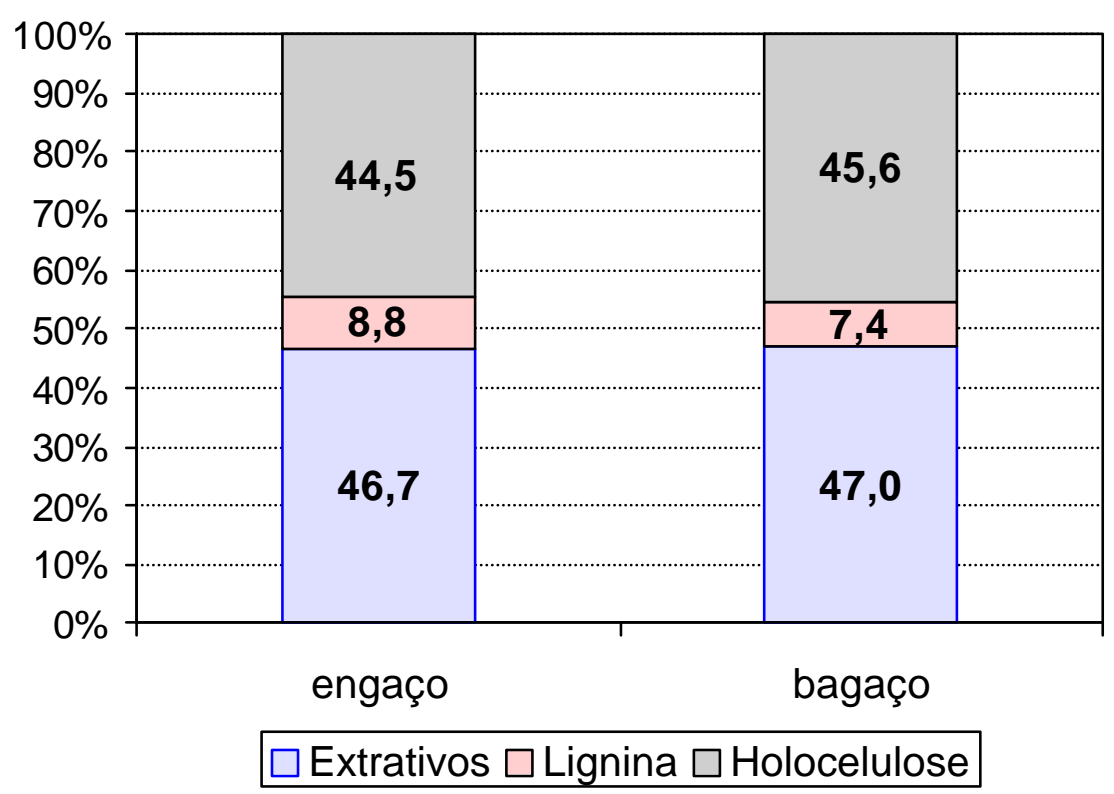

Figura 10 - Composição química do engaço e do bagaço

Destaca-se na Figura 10 o elevado teor de extrativos, os quais são indesejados para processos químicos de polpação por consumirem parte da carga alcalina em reações secundárias.

O bagaço, quando considerado como matéria-prima para produção de polpa celulósica, possui vantagens como facilidade de manuseio e transporte, e alimentação do digestor, além de permitir melhor aproveitamento do volume útil deste equipamento. A secagem do bagaço também é facilitada devido a sua maior área superficial, prevenindo problemas com degradação biológica, o que é de fundamental importância para o armazenamento. Isto possibilita a estocagem desse material como uma alternativa para suprir problemas relacionados com a sazonalidade da produção de banana.

A forma de bagaço proporciona maior facilidade de penetração do licor de cozimento, durante processos de polpação química, devido a maior área superficial em relação ao engaço na sua forma original. 


\subsection{Pré-tratamentos}

Considerando-se o elevado teor de extrativos totais presentes no bagaço, neste trabalho foram consideradas 3 alternativas (pré-tratamentos) para remoção destes componentes: lavagem, pré-extração aquosa, e lavagem seguida de pré-extração aquosa.

A ação da água e solventes neutros em vegetais está sobretudo nos extrativos, e a extração desses componentes é tanto mais rápida quanto mais subdividido esteja o material (Brito, 1985). No caso do bagaço, que possui suas estruturas anatômicas desagregadas, espera-se maior facilidade em promover a remoção de extrativos solúveis em água através de um processo de lavagem.

Hydholm (1965), recomenda o uso do processo de "hidrapulper" para realizar a lavagem de materiais com alto teor de medula.

A etapa de lavagem seguida de pré-extração aquosa foi empregada utilizando os métodos descritos consecutivamente, com os objetivos de verificar a eficiência dos tratamentos realizados sucessivamente e se houve efeito sinérgico ou aditivo desses tratamentos aplicados ao engaço de bananeira.

$\mathrm{Na}$ Tabela 7 estão apresentados os rendimentos médios e

composição química dos bagaços tratados: lavado, pré-extração aquosa e lavado seguido de pré-extração aquosa. 
Tabela 7. Rendimentos e composições químicas dos bagaços tratados

\begin{tabular}{llrcc}
\hline \multicolumn{2}{c}{ Parâmetros } & Lavagem & Pré-extração & $\begin{array}{c}\text { Lavagem/ } \\
\text { Pré-extração }\end{array}$ \\
\hline Rendimento (\%) & Média & 58,14 & 59,46 & 53,55 \\
& C. V. & 1,45 & 1,13 & 4,14 \\
& Extrativos & 16,83 & 9,80 & 9,06 \\
Composição & Lignina & 11,76 & 10,37 & 12,16 \\
química (\%) & Holocelulose & 71,41 & 79,83 & 78,78 \\
\hline
\end{tabular}

Os resultados apresentados na Tabela 7 mostram que a etapa de lavagem do bagaço, pode remover cerca de $41,86 \%$ do material original (bagaço sem tratamento), principalmente extrativos. Este valor está relacionado com o teor de extrativos solúveis em água.

Os resultados da Tabela 7 mostram que a etapa de pré-extração aquosa pode remover $40,54 \%$ do engaço. A etapa de lavagem e pré-extração aquosa removeu $46,45 \%$ da constituição do material.

A associação dos resultados de rendimento e composição química dos materiais obtidos permite calcular a eficiência de remoção de extrativos para os tratamentos considerados neste trabalho, os quais são apresentados na Figura 11. 


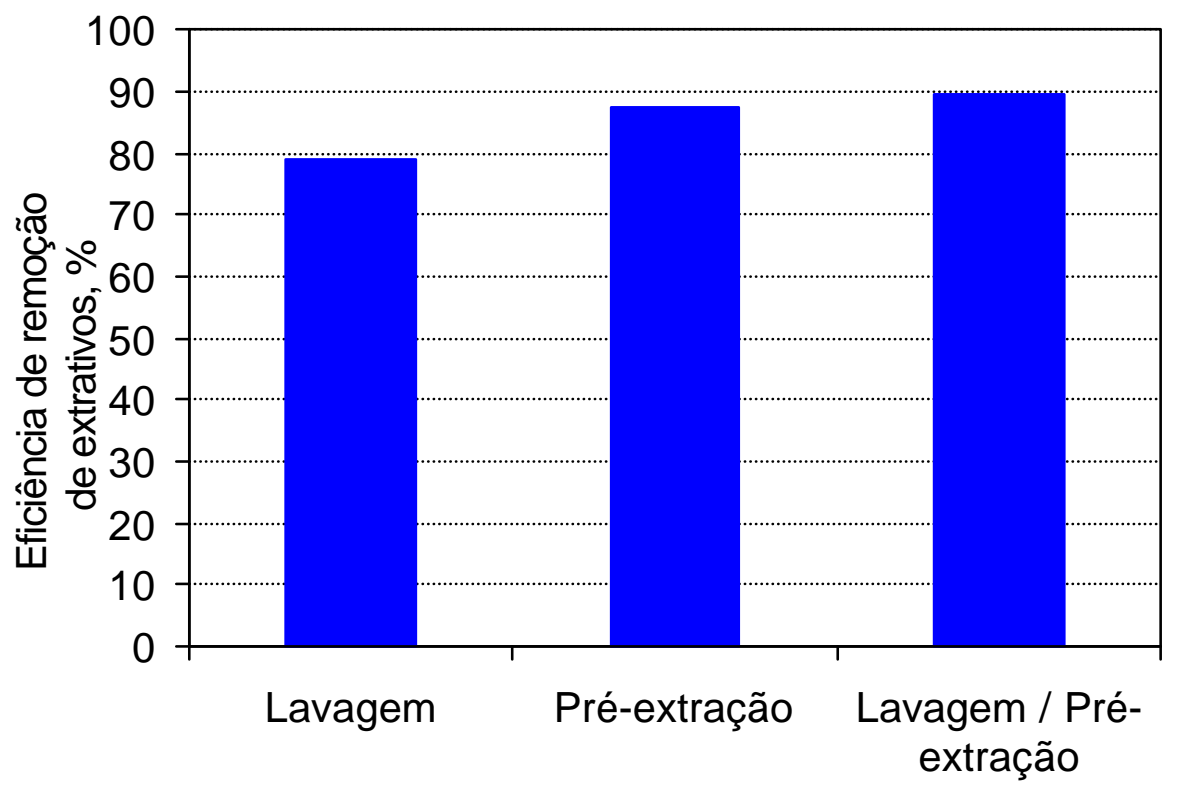

Figura 11 - Eficiência de remoção de extrativos do bagaço pelos tratamentos: lavagem, pré-extração aquosa e lavagem seguida de pré-extração aquosa

A etapa de lavagem apresenta eficiência de remoção de extrativos de aproximadamente $79 \%$; já as etapas de pré-extração aquosa e lavagem seguida de pré-extração aquosa apresentam eficiências superiores, 87,6\% e $89,7 \%$ respectivamente.

A definição de um processo para o pré-tratamento do bagaço deve considerar não apenas a eficiência do processo, mas também os custos de investimento e operação do processo. A etapa de lavagem empregada como pré-tratamento para polpação do engaço de bananeira possui algumas vantagens sobre a etapa de pré-extração aquosa, como maior facilidade e simplicidade operacional e menor custo de processo.

Os resultados apresentados da Tabela 7 indicam que a lavagem poderia ser uma alternativa apropriada para remoção de extrativos, que pode ser indicada antes de qualquer processo de polpação a ser realizado, 
principalmente antes de processos químicos ou semiquímicos, onde se utilizam reagentes químicos. A etapa de lavagem resulta num material com menor teor de extrativos e consequentemente apresentará maior teor de holocelulose e de lignina em relação ao bagaço original.

Considerando-se os aspectos mencionados anteriormente, em especial os relacionados àfacilidade operacional e investimentos necessários à implantação, a etapa de lavagem apresenta-se como mais vantajosa para o pré-tratamento do bagaço. Em escala industrial a etapa de lavagem poderá ser realizada num filtro atmosférico conforme o esquema da Figura 12.

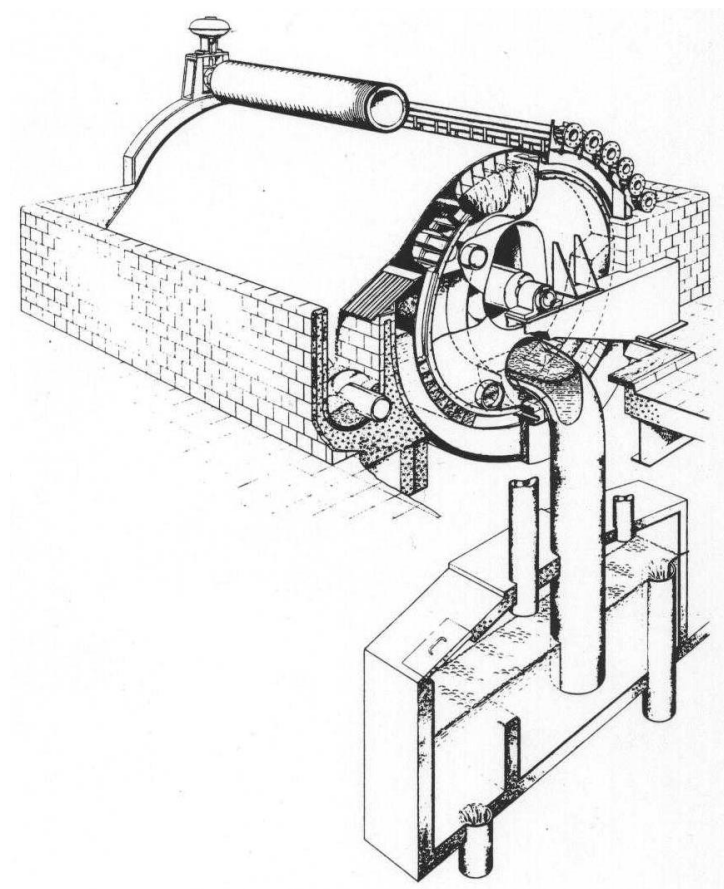

Figura 12 - Filtro atmosférico (Smook, 1994)

\subsection{Polpação}

A produção de polpa celulósica a partir do bagaço do engaço de bananeira deve considerar os aspectos intrínsecos da atividade bananicultora e entre eles estão os aspectos ambientais, os quais devem ser considerados para a definição do processo de polpação. O processo cal, empregado neste 
trabalho apresenta um baixo custo operacional e a lixívia gerada apresenta potencialidade para sua utilização como elemento de correção de acidez do solo, a qual pode ser utilizado no próprio bananal.

A Figura 13 apresenta os resultados dos rendimentos totais dos cozimentos com cal $(\mathrm{CaO})$.

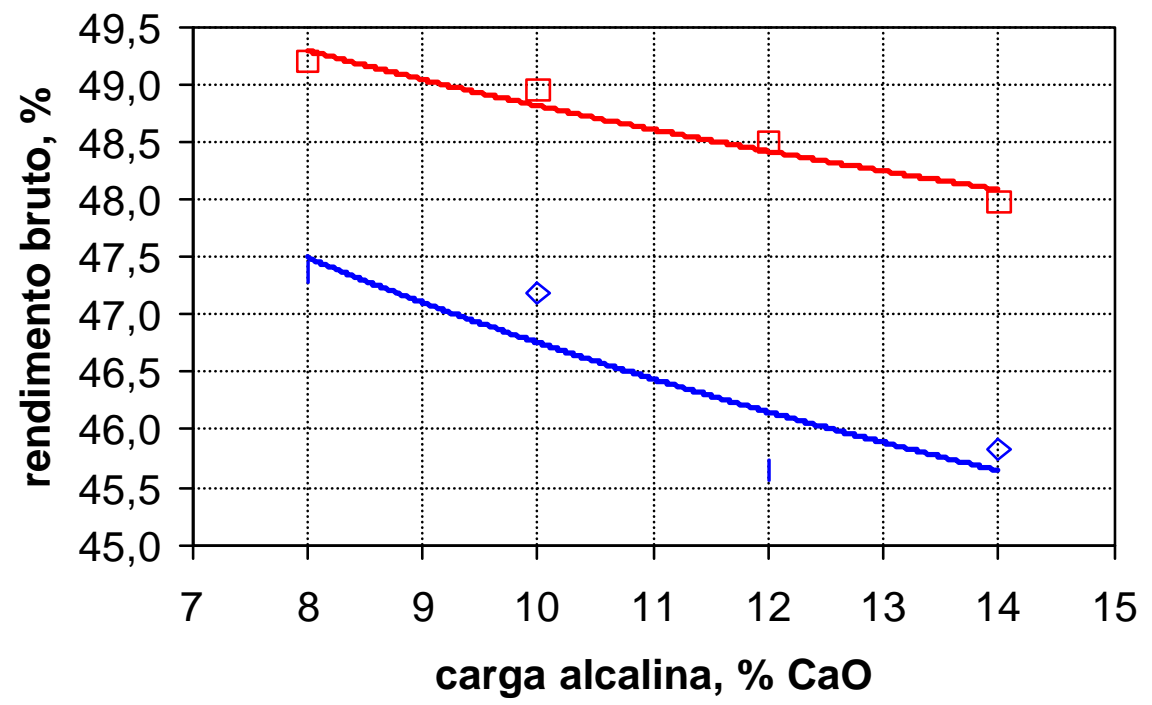

I original $\square$ lavado

Figura 13 - Rendimentos - Polpação cal $(\mathrm{CaO})$ - Bagaço original (sem tratamento) e bagaço lavado.

O aumento da carga alcalina $(\mathrm{CaO})$ tem como conseqüência a redução no rendimento bruto, sendo considerado típico para esse processo, uma vez que a carga alcalina promove degradação tanto da lignina, dos extrativos como dos carboidratos. O processo de lavagem traz como efeito benéfico um maior rendimento no processo de polpação.

Os cozimentos testemunha ( $\mathrm{NaOH} 12 \%$ ) para o bagaço original e para o bagaço lavado apresentaram rendimentos brutos de $37,8 \%$ e $38,8 \%$ 
respectivamente. A análise comparativa destes resultados com os apresentados na Figura 13 mostram que o processo cal apresenta rendimentos superiores ao processo soda para o bagaço do engaço da bananeira.

A avaliação de um processo de polpação deve considerar também a eficiência de deslignificação. Este aspecto é especialmente importante para polpas que serão destinadas ao processo de branqueamento. Na Figura 14 apresentam-se os resultados do teor de lignina residual presentes nas polpas obtidas.

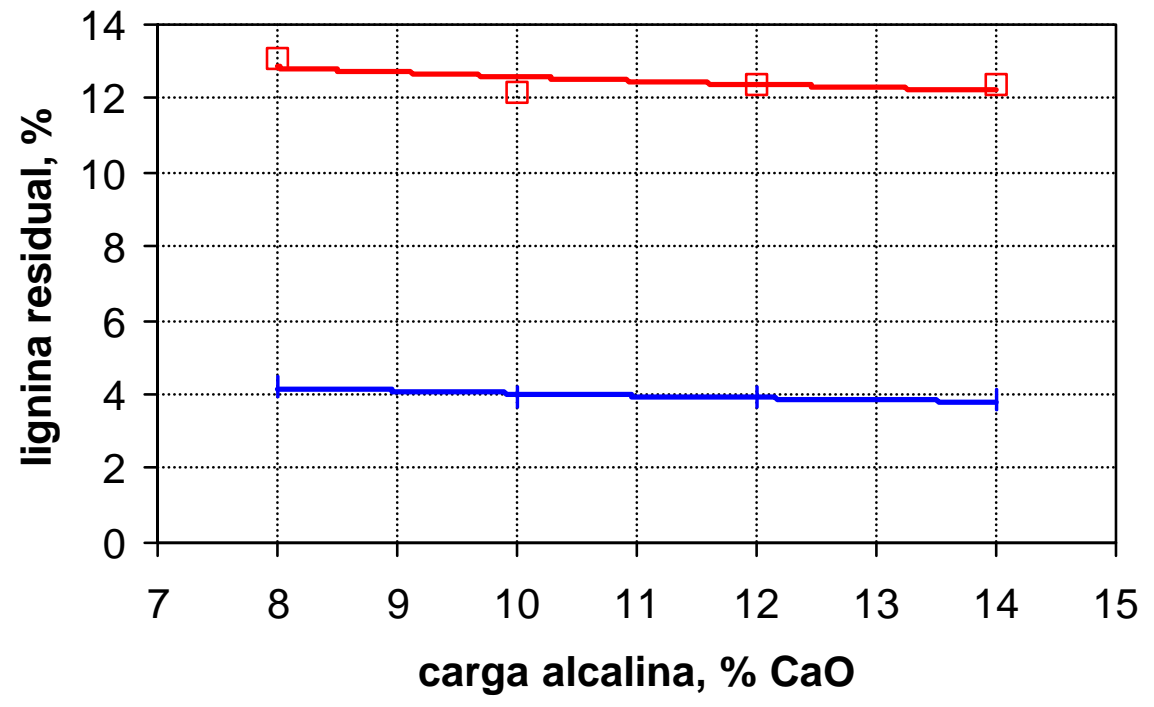

Figura 14 - Teor de lignina residual em função da carga alcalina

A carga de $\mathrm{CaO}$ não apresenta efeito significativo sobre o teor de lignina residual das polpas obtidas. Estes resultados estão de acordo com Grant (1966) que relata que a ação da cal sobre as fibras possui um limite de ação, e que este reagente necessita ser constantemente agitado durante o processo de cozimento, para que ocorra melhor homogeneidade de reação sobre a matéria- 
prima. Aumentos da carga alcalina $(\mathrm{CaO})$ não trazem significativas alterações nas reações de polpação.

$\mathrm{Na}$ Figura 14 observa-se que o teor de lignina residual nas polpas oriundas do bagaço lavado é aproximadamente 3 vezes ao das polpas não lavadas. É necessário porém considerar que o teor de lignina no bagaço lavado é significativamente superior em $4,4 \%$ ao do bagaço original, $11,8 \%$ e $7,4 \%$ respectivamente. Considerando-se estes aspectos e associando-se os valores de rendimento, teor de lignina inicial e residual das polpas, pode-se determinar a eficiência de deslignificação (Figura 15).

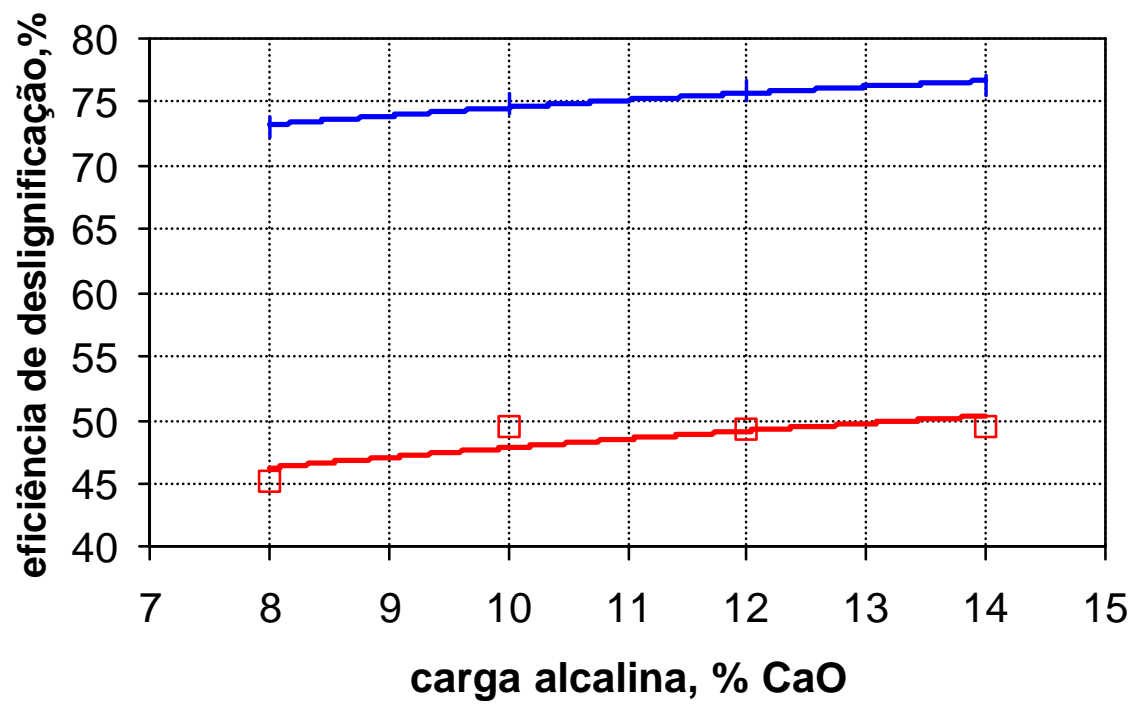

I original $\square$ lavado

Figura 15 - Eficiência de deslignificação em função da carga alcalina 


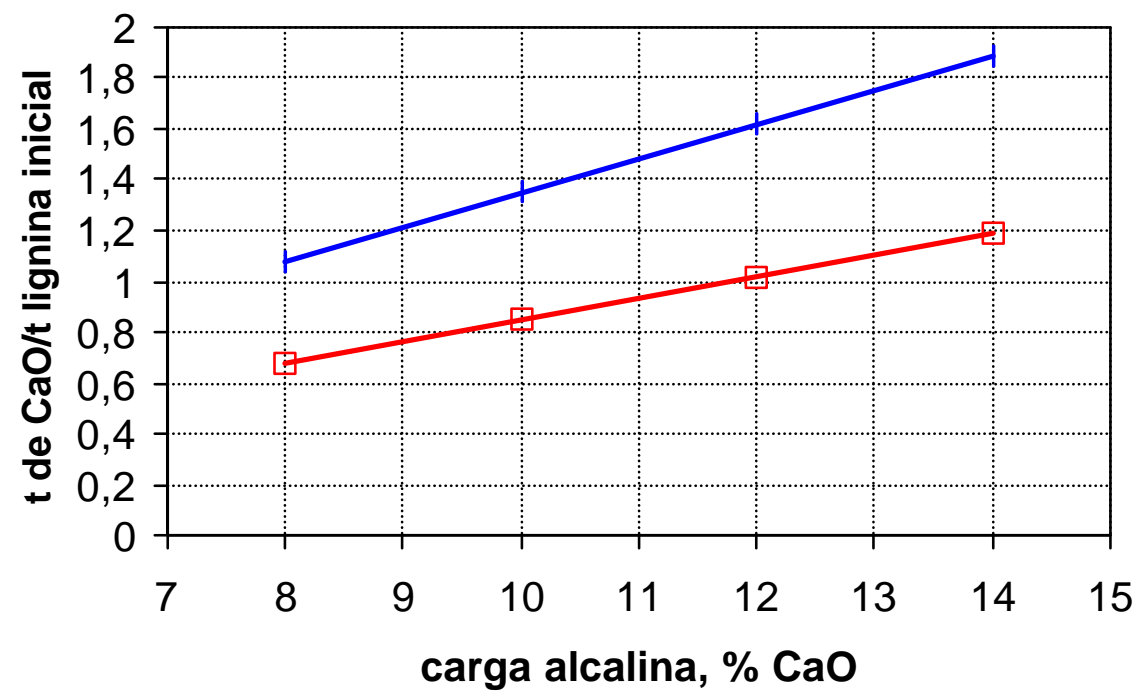

। original $\square$ lavado

Figura 16 - Carga especifica de $\mathrm{CaO}$ - t de $\mathrm{CaO} / t$ de lignina inicial.

Os resultados iniciais mostram que, como o teor de lignina no bagaço original é menor, do que no bagaço lavado, a carga específica de $\mathrm{CaO}$ em relação àquantidade de lignina é maior para o bagaço original. Calculando-se a relação entre as cargas específicas para o bagaço original e bagaço lavado tem-se um valor de 1,59. Fazendo-se o mesmo cálculo para o valor de eficiência de deslignificação (Figura 15) obteve-se um valor médio de 1,6. Estes resultados mostram que a diferença de deslignificação entre os materiais considerados está relacionada àcarga específica de $\mathrm{CaO}$ aplicado.

Os valores obtidos para deslignificação do engaço estão de acordo com Silva (1998) que avaliou o pseudocaule de bananeira sob o mesmo aspecto. Este autor observou que o pseudocaule possui grande dificuldade de deslignificação, mesmo aplicando-se $30 \%$ de álcali ativo em processo kraft, obteve-se número kappa 34 . O aumento da carga alcalina de 10 para 17,5 resultou em decréscimo do número kappa de 67,0 para 33,9. Entretanto aumentos adicionais de até $30 \%$, não causou nenhuma deslignificação 
adicional. O autor levanta a hipótese de atribuir esse fato àrealização da prévia secagem do pseudocaule, que permanece com material fortemente aderido as fibras, constituído principalmente por células de parênquimas que dificultam a deslignificação do material.

Os teores de lignina residual para os tratamentos testemunha $(\mathrm{NaOH}$ $12 \%$ ) são de 3,8 e 4,7 respectivamente para o bagaço original e lavado. Estes valores, quando considerados os teores iniciais de lignina, correspondem a uma eficiência de deslignificação de $81 \%$ e $85 \%$ para o bagaço original e lavado respectivamente. Estes dados mostram, conforme esperado, que o processo soda é mais eficiente em termos de remoção de lignina.

Os teores de lignina residual para o processo cal $(8,10,12$ e $14 \%$ de $\mathrm{CaO})$ do bagaço original são próximos aos valores para obtidos para 0 processo soda $(12 \% \mathrm{NaOH})$, enquanto os resultados para o bagaço lavado no processo cal foram de 3 vezes superiores aos do processo soda.

\subsection{Fluxograma de unidade industrial}

Considerando-se os resultados obtidos neste trabalho, apresenta-se a seguir um fluxograma básico de uma unidade industrial para o processamento do engaço da bananeira (Figura 17). Este fluxograma tem como premissas que será utilizado o engaço na forma de bagaço, um processo de lavagem deste material e o posterior processo cal $(\mathrm{CaO})$ de polpação. A polpa obtida será desaguada e devido æ̀s características de suas fibras e disponibilidade de matéria-prima deverá ser utilizada como componente de mistura (em baixa proporção - 10 a $20 \%$ em peso) na produção de papéis de embalagem não branqueados e também de papéis especiais. 


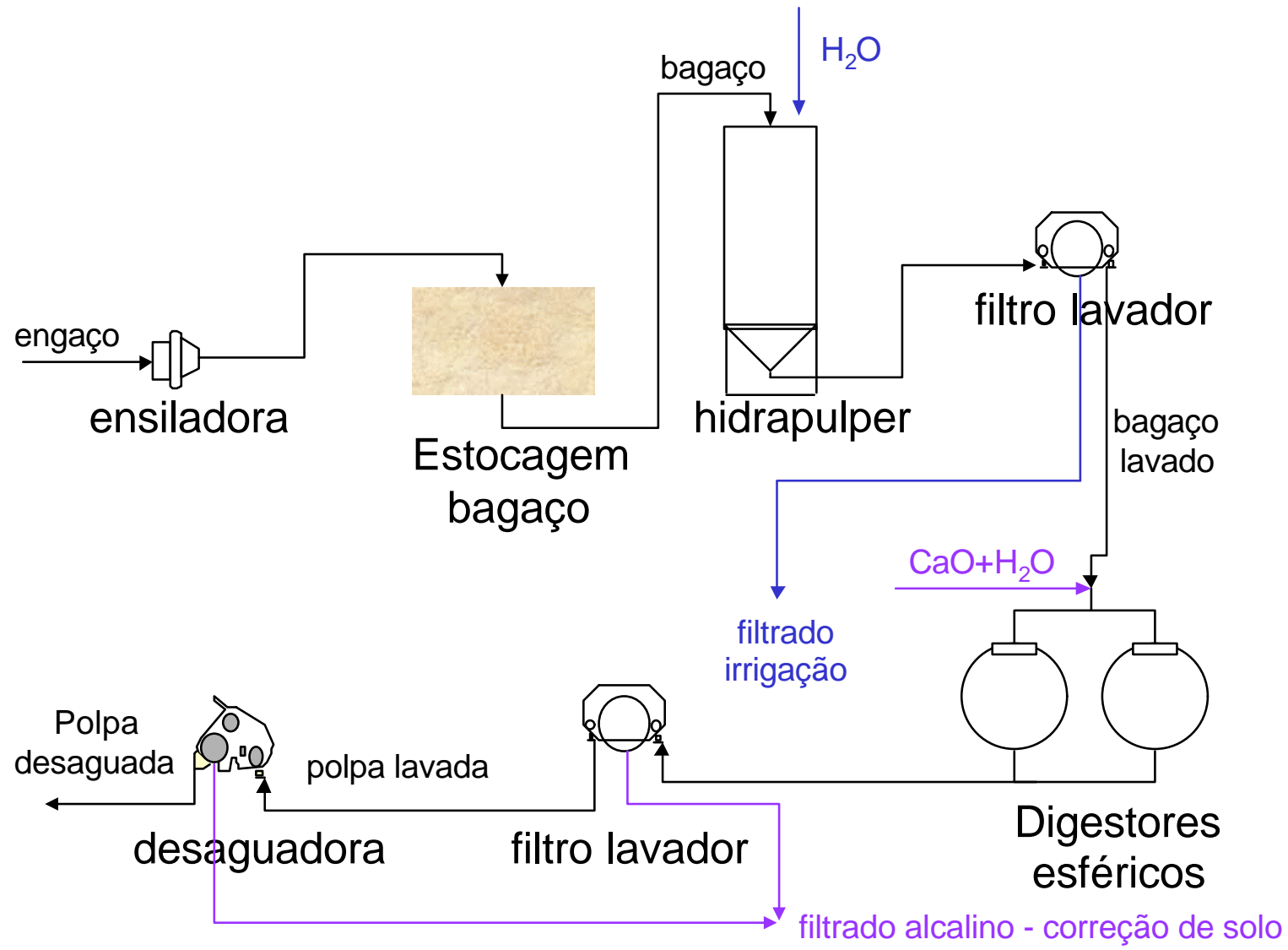

Figura 17 - Fluxograma básico de unidade de produção de polpa celulósica a partir do engaço da bananeira. 


\section{CONCLUSÕES}

Os resultados obtidos neste trabalho permitem concluir que:

- as fibras do engaço de bananeira são classificadas como longas e possuem características morfológicas que permitem sua utilização como matériaprima produção de polpa celulósica, visando a fabricação de papel.

- o engaço se caracteriza por um elevado teor de extrativos totais, $46,8 \%$, (sendo $30,4 \%$ solúveis em água), e baixo teor de lignina.

- a morfologia do engaço (alongada) dificulta seu processamento industrial para produção de polpa celulósica.

- a produção de bagaço a partir do engaço de bananeira utilizando-se ensiladora desagregadora é uma alternativa tecnicamente viável e recomendável, pois não altera significativamente as características químicas e morfológicas das fibras do engaço. Este processo pode ser considerado como uma etapa do processo de produção de polpa celulósica do engaço, pois traz benefícios relacionados àfacilidade de manuseio e secagem deste material, e melhor aproveitamento do volume útil de digestores. 
- a etapa de lavagem do bagaço apresenta elevada eficiência em termos de remoção de extrativos e dada àsua facilidade de implementação em escala industrial deve ser considerada como uma etapa do processo de produção de celulose a partir do bagaço do engaço da bananeira.

- O processo cal pode ser considerado como uma alternativa tecnicamente viável para produção de polpa celulósica a partir do bagaço do engaço da bananeira. A polpa obtida deve ser utilizada como componente de mistura (em baixa proporção) na fabricação de papéis de embalagem não branqueados ou para produção de papéis especiais. 


\section{REFERÊNCIAS BIBLIOGRÁFICAS}

ABEL-REHIM, S.A.; TARABOUSI, M.A. Mechano-chemical depithing of bagasse. In: TECNOLOGY ASSOCIATION PULP AND PAPER INTERNATIONAL. Non wood plant fiber pulping. Atlanta: TAPPI Press, 1987. p.137-143. (Progress Report, 17)

ASSOCIAÇÃO BRASILEIRA TÉCNICA DE CELULOSE E PAPEL - Normas da Associação Brasileira de Celulose e Papel. São Paulo: ABTCP, 1999. 1v.

ANUÁRIO ESTATÍSTICO DO BRASIL-1996, v. 56, p.3-52, 1996.

ANUÁRIO ESTATÍSTICO DO BRASIL- 1998, v. 58, p.3-26, 1998.

ARRUDA, S.T.; PÉREZ, L.H.; BESSA JUNIOR, A.A. A Bananicultura no Vale do Ribeira: características dos sistemas de produção. Agricultura em São Paulo, v.40, n.1, p.1-17, 1993.

ATCHISON, J.E.; BOEHM, R.M.; CARR, W.F.; JENNESS, L.C.; KURRLE, F.; LYON, J.R.; MCKEE, R.H.; O'NEIL, F.W.; SUTHERLAND, D.G.; TUCKER, L.B. Otros processos de obtención de pulpas, 12. In: LIBBY, C.E. Ciencia y tecnología sobre pulpa y papel. México: Compañia Editorial Continental, 1967. v.1, p. 393-426. 
ATCHISON, J.E. Bagasse. In: TAPPI/Tecnology association pulp and paper international Pulp and paper manufacture secondary fibers and nonwood pulping. 3.ed. Montreal: CPPA; TAPPI, 1987. v. 3, p.22-70.

BARBOSA, A.C.F.B.; SOFFNER, M.L.A.P.; SILVA Jr., F.G.; ZENID, G.J.; TOMAZELLO FILHO, M.; COSTA, A.D.C. Metodologia para preparo de cortes histológicos de materiais com elevado teor de umidade: aplicação para o engaço de bananeira. In: SIMPÓSIO DE ATUALIZAÇÃO DE TÉCNICAS DE MICROSCOPIA, Curitiba, 1999. Curitiba: UFPR, 1999. p. 55.

BARRICHELO, L.E.G.; BRITO, J.O. A madeira das espécies de eucalipto como matéria-prima para a indústria de celulose e papel. Série divulgação PRODEPEF, n.13, p.1-145, 1976.

BENATTI JUNIOR, R. Rami: planta têxtil e forrageira. São Paulo: Fundação Cargill, 1988. 76 p.

BLANCO ROJAS, M.L. Beneficiamento e polpação da Ráquis da bananeira "Nanicão" (Musa Grupo AAA, "Giant Cavendishii”) Piracicaba, 1996. 150 p. Dissertação (Mestrado) - Escola Superior de Agricultura "Luiz de Queiroz", Universidade de São Paulo.

BRITO, J.O. Química da madeira. Piracicaba: ESALQ, 1985.126 p.

COSTA, M.M.; COLODETTE, J.L.; FOELKEL, C.E.B. - Aspectos básicos da produção de polpa solúvel II : uma revisão. O Papel, v.59, n.9, p.66-72. set.1998. 
CRONQUIST, A. An integrated system of classification of flowering plants. New York: Columbia University Press, 1981. 1262 p.

D’ALMEIDA, M.L.O. Celulose e papel: tecnologia de fabricação do papel. 2.ed. São Paulo: SENAI; IPT, 1988.964p.

DARKWA, N.A. Pulping characteristics of plantain (Musa paradisiaca L.) pseudostems. North Carolina, 1978. 138 p Thesis (Ph.D.) - North Carolina State University.

DARKWA, N.A. Pulping chemical of plantation (Musa paradisiaca L.) pseudstems. In: INTERNATIONAL NON-WOOD FIBER PULPING AND PAPERMAKING CONFERENCE. Beijing, 1988. Proceedings. s.l.: s.ed, 1988. v. 2, p. 973-974.

DARKWA, N.A. Plantain (Musa paradisiaca L.): A fibre source for tropical countries In: 1998 PULPING CONFERENCE, Montreal, 1998. Atlanta: TAPPI, 1998. 3 v. Proceedings. p.645-649.

ENGLER, A. Syllabur der pflanzenfamilien. 12.ed. Berlin: Gebruder Borntraeger, 1954. v.1

FAO. FAO Statistical Databases. 10 julho de 2001.

FIGUEIREDO, P.S. A sociedade do lixo: os resíduos, a questão energética e a crise ambiental. Piracicaba: UNIMEP, 1995. P. 47-56.

FOELKEL, C.E.B.; BARRICHELO,L.E.G. Tecnologia de celulose e papel. Piracicaba: ESALQ, 1975. 207p. 
FOELKEL, C.E.B. Madeira de eucalipto: da floresta ao digestor. Piracicaba: ESALQ, 1977.25 p.

GARAVELLO, M.E.P.E.; SOFFNER, M.L.A.P. Relatório técnico: viabilidade de implantação de planta piloto de produção de papel especial com fibra de bananeira. Piracicaba: ESALQ, 1997. 30p.

GOWEN, S. Bananas and plantains . London: Chapman \& Hall, 1996. 612p.

GRANT, J. Manual sobre la fabricacion de pulpa y papel. Mexico: Compañia Editorial Continental S.A., 1966. cap. 2, p. 35-89: Materias-primas fibrosas: obtención de pulpas.

HIROCE, R. O Aproveitamento do pseudocaule. O Estado de São Paulo, 19 mar. 1972. Suplemento Agrícola 877, p.11.

INSTITUTO CENTROAMERICANO DE INVESTIGACION Y TECNOLOGIA INDUSTRIAL- ICAITI. The prodution of pulp and paper from the stems of the fruit, pseudstem of the leaves of the banana plant, using conventional (kraft, full soda) and non conventional process (organosolv). Guatemala, 1988. 53p. (Projeto: Integrated Utilization of Banana Plant. Final Report).

JARMAN, C. G.; MYKOLUK, S.; KENNEDY,L.; CANNING,A.J. Banana fibre: a review of its properties and small-scale extraction and processing. Tropical Science, v. 19, n. 4, p. 173-185, 1977.

KLUGE, R.A.; SCARPARE FILHO, J.A.; VICTÓRIA FILHO, R. Densidade e sistema de espaçamento de bananeiras "nanicão" (Musa AAA subgrupo 
Cavendisii): produção de ráquis e relação ráquis/cacho. Scientia Agricola, v. 56, n 4, p. 811-818, 1999.

MEDINA, J.C. O sisal. São Paulo: SCASP, 1954. 285 p.

MEDINA, J.C. Plantas fibrosas da flora mundial. Campinas: Instituto Agronômico de Campinas, 1959. 913p.

MEDINA, J. C. Banana Campinas: Instituto Agronômico de Campinas, 1961. $61 \mathrm{p.}$

MELO, J.R. Identificação micrográfica de fibras celulósicas: contribuição para análise de pastas e papéis. Angola: Instituto de Investigação Agronômica de Angola (IIAA. Série Científica, 31) 1973. 76 p.

MONTALVÃO FILHO, A.; GOMIDE, J.C.; CONDÉ, A. R. Polpação kraft de bambu com pré-extração aquosa. In: CONGRESSO ANUAL DA ABTCP, 18., São Paulo, 1984, São Paulo: ABTCP. 1984. p. 169-180.

MOREIRA, R.S. Teoria e prática de cultivo. Campinas: Fundação Cargill, 1987. $335 \mathrm{p}$.

NOLASCO, A.M. Utilização de resíduos da indústria de papel na produção de materiais para construção civil. São Carlos, 1993. 171 p. Dissertação (Mestrado). Escola de engenharia de São Carlos, da Universidade de São Paulo.

PAULA, J.E.; ALVES, J.L.H. Madeiras nativas: anatomia, dendrologia, dendrometria, produção e uso. Brasília: Fundação Mokiti Okada, 1997. $543 p$. 
ROCHELLE, L.A.; RODRIGUES, R.R.; CAPELLARI JUNIOR, L. Famílias de plantas fanerogâmicas de interesse econômico. Piracicaba: CALQ, 1991. 57p.

RODÉS, L. Plantas fibrosas anuais. São Paulo, IPT; CTCP, 1984. 45p.

RYDHOLM, S.V. Pulping process . New York: Interscience, 1965. 1269p.

SABÓRIO, C.M. Produción de papel y cartón a partir de raquis de banano. San José, 1981. 57 p. Trabajo (Licenciatura) - Universidad de Costa Rica.

SHEDDEN, M. Estudio de raquis de banano (Musa giant cavendishii Lambert) e investigación de sus possibles usos. San José, 1978. 96 p. Trabajo (Licenciatura) - Univesidad de Costa Rica.

SILVA, A. G. Utilização do pseudocaule de bananeira para produção de celulose e papel. Viçosa, 1998. 90 p. Dissertação (M.S.) - Universidade Federal de Viçosa.

SIMÃO, S. Manual de fruticultura. Piracicaba: ESALQ, 1971. Cap. 3. p.230258: Banana.

SIMMONDS, N.W. Bananas. 1.ed. London: Tropical Agriculture Series, 1959. $466 \mathrm{p}$.

SIMMONDS, N.W. Bananas. 2.ed. London: Tropical Agriculture Series, 1966. $512 \mathrm{p}$. 
SMOOK, G.A. Handbook for pulp \& paper technologists. Vancouver: Angus Wilde Publications, 1994. 419 p.

SOFFNER, M.L.A.P.; NOLASCO, A.M.; NOLASCO, A.C.; MILAN, M. Mechanical extraction of banana fiber - Musa cavendishii, nanicão variety. In: INTERNATIONAL SYMPOSIUM ON NATURAL POLYMERS AND COMPOSITES, 2., Atibaia, 1998. Proceedings. São Carlos: EMBRAPA, 1998. p. $189-190$.

SOTO BALLESTERO, M. Bananos: cultivo y comercialización. 2.ed. San José: Litografia e Imprenta LIL, 1992. 674p.

TECNICAL ASSOCIATION OF THE PULP AND PAPER INDUSTRY. Testing methods. Atlanta: Tappi, 1992. 2v.

TOMAZELLO FILHO, M. Apostila: Formação e Anatomia da Madeira. Exercícios práticos. Piracicaba: ESALQ, 1998. 76 p.

TORRES, M. Propriedades fundamentales de la fibra de raquis de banano (Musa giant cavendishii). San José, 1981. 31 p. Trabajo (Licenciatura) Universidad de Costa Rica). 